Article

\title{
An Analysis of Environmental Efficiency and Environmental Pollution Treatment Efficiency in China's Industrial Sector
}

\author{
Xiao-Ning $\mathrm{Li}^{1}{ }^{1}$, Ying Feng ${ }^{2} \mathbb{D}$, Pei-Ying $\mathrm{Wu}^{3} \mathbb{D}$ and Yung-Ho Chiu ${ }^{4, *(\mathbb{D})}$ \\ 1 Business College, Northwest University of Political Science and Law, No. 558 West Chang An Road, \\ Chang An District, Xi'an 710122, China; lixiaoning76@163.com \\ 2 Department of Auditing, Business College, Institute of Resource Conflict and Utilization, Northwest \\ University of Political Science and Law, No. 558 West Chang An Road, Chang An District, Xi'an 710122, \\ China; yingfeng8410@126.com \\ 3 Department of Applied Foreign Languages, Cheng Shiu University, No. 840, Chengcing Road, Niaosong \\ District, Kaohsiung City 83347, Taiwan; yiyi6622@gmail.com \\ 4 Department of Economics, Soochow University, No. 56, Kueiyang Street Section 1, Taipei 100, Taiwan \\ * Correspondence: echiu@scu.edu.tw; Tel.: +886-2-23111531 (ext. 5201); Fax: +886-2-27976015
}

check for

updates

Citation: Li, X.-N.; Feng, Y.; Wu, P.-Y.; Chiu, Y.-H. An Analysis of Environmental Efficiency and Environmental Pollution Treatment Efficiency in China's Industrial Sector. Sustainability 2021, 13, 2579. https:// doi.org/10.3390/su13052579

Received: 2 February 2021

Accepted: 23 February 2021

Published: 28 February 2021

Publisher's Note: MDPI stays neutral with regard to jurisdictional claims in published maps and institutional affiliations.

Copyright: (c) 2021 by the authors. Licensee MDPI, Basel, Switzerland. This article is an open access article distributed under the terms and conditions of the Creative Commons Attribution (CC BY) license (https:/ / creativecommons.org/licenses/by/ $4.0 /)$.

\begin{abstract}
This research adopts the meta Dynamic Directional Distance Functions (DDF) model in order to calculate the environmental efficiency and environmental governance efficiency of China's industrial sector from 2010 to 2017 from the overall, sub-regional, and sub-provincial perspectives and discusses the technical gaps in regional environmental pollution control and the reasons for ineffective environmental governance. The research results show that the overall level of environmental governance efficiency in China's industrial sector is relatively high over this time period, and the group frontier calculation results have improved compared to the meta frontier. The actual technical level of the high-income group is closest to the potential technical level, and the upper-middle income group is still far from the potential technical level. The main reason for the ineffective environmental governance of the provinces in the high-income group is ineffective management, while the main reason for ineffective environmental governance of the provinces in the upper-middle-income groups is technical inefficiency. Regardless of high-income groups or upper-middle-income groups, each province's inefficiency of environmental governance is caused by inefficiency of the input factors.
\end{abstract}

Keywords: environmental efficiency; environmental governance efficiency; meta dynamic DDF model; chinese industrial sector

\section{Introduction}

The rapid growth of China's environmental protection investment has strongly promoted the country's economic and social transformation to green development. From 2013 to 2018 , investment in its ecological protection and environmental management industry increased by an average annual rate of $31.4 \%$, and in 2018 the central government employed 255.5 billion yuan in pollution prevention and ecological protection funds. Although the current investment in environmental pollution control in China has increased exponentially, the beneficial effect of environmental pollution control is not significant, and environmental quality is still worrying (Zheng and Zhao [1]). According to the "Communiqué of the First National Pollution Source Survey", industrial pollution sources are one of the three major types of environmental pollution. Statistics from the Ministry of Environmental Protection show that over $90 \%$ of pollution comes from industry. Therefore, efficient treatment of industrial pollution is the key to environmental governance.

The rapid growth of the Chinese economy has always come at the cost of huge energy consumption and environmental damage. At present, it is the world's second largest economy and energy-consuming country, and the discharge of various types of pollution is close to the self-recovery limit of the environment, thus placing extreme pressure on 
environmental pollution control. The Chinese government has taken corresponding measures against air pollution. In addition to launching the "National Ambient Air Quality Standard", which was fully implemented on 1 January 2016, the following areas show what actions are being taken.

Investment Department of the National Bureau of Statistics: The continuous improvement in the level of fixed asset investment continues to play a key role in national development, as evidenced by the ninth series of reports on economic and social development achievements during the 70th anniversary of the founding of modern China. (2) Environmental Technology Efficiency, Pollution Control, and Environmental Performance: An analysis based on China's provincial panel data from 1998 to 2012 set up the implementation to require that PM2.5 reach a national standard of 35 micrograms/cubic meter by 2030. At the same time, "13th Five-Year Plan" aims for sulfur dioxide emissions to reach a peak before 2030. Premier Li Keqiang noted in the "Government Work Report" of the National Sessions in 2019 that the emissions of sulfur dioxide and nitrogen oxides fell by $3 \%$ in 2019, and the concentration of fine particulate matter (PM2.5) in key areas will continue to decline. It is thus necessary to strengthen industry and coal burning. (3) Treatment of the three major pollution sources of motor vehicles. Therefore, in terms of environmental governance, one can see that the China government's determination and actions toward the environment have always been very strong. However, due to the long-term use of the extensive economic development model of high material, high energy consumption and high pollution, there is still a certain gap between the efficiency of China's industrial pollution control and theoretical expectations. Therefore, in the context of China's continuous strengthening of industrial pollution control facilities and costs and innovative pollution control technologies, this study will use the meta Dynamic DDF model to scientifically evaluate the environmental governance efficiency of the industrial sectors in 30 provinces and cities in China from 2010 to 2017. Thereby, we can objectively and accurately understand the history and current situation of China's industrial pollution and treatment, and provide a basis for policy formulation to improve the efficiency of industrial pollution treatment. The research in this paper has the following contributions. First, it fully considers the two aspects of energy utilization and pollution control, so as to comprehensively and systematically calculate the environmental efficiency and environmental pollution control efficiency of the industrial sector; second, in the research method, adopting the dynamic DEA concept can evaluate the efficiency of environmental pollution control in different periods. The introduction of the meta concept effectively overcomes the heterogeneity of decision-making units. The meta DDF distance function model makes the evaluation results more accurate; third, the various inputs and a detailed analysis of the output elements can clearly understand the specific reasons for the insufficient efficiency of environmental pollution control in the industrial sector to formulate targeted improvement measures.

The rest of this study runs as follows. Section 2 is a literature review. Section 3 is the research method. Section 4 is the empirical results. Section 5 is the conclusions and policy implications.

\section{Literature Review}

Academic circles have taken different perspectives on environmental efficiency, but the names they use are not necessarily the same. In order to accurately define the different connotations of environmental efficiency and conduct an appropriate analysis, this research denotes the term eco-efficiency to be the input ratio measured after energy and environmental factors are incorporated into the production activities of an enterprise, industry, or region. The economic value created by a unit of energy and environmental load effectively improves an economy's overall benefits and social welfare under the condition of limited energy and environmental resources (Zeng and Niu [2]). Environmental pollution control efficiency (or environmental pollution treatment efficiency) refers to the technical efficiency calculated by taking the pollution discharge and pollution control investment in 
the production process as input and the pollution control amount as the output, expressed as the ratio of investment in environmental treatment to the reduction in pollutants ( $\mathrm{Tu}$ et al. [3]). Environmental efficiency measures the friendliness of different industries or regional economic development to the energy environment, while environmental pollution control efficiency measures the effectiveness of environmental pollution control. These two indicators reflect energy utilization and environmental pollution.

Results in the literature on environmental efficiency and environmental pollution control efficiency are relatively fruitful. Song et al. [4] proposed a radial slack-based model (RSBM) and an RSBM-Malmquist-Luenberger index to evaluate provincial environmental efficiencies in China from 2004 to 2012, showing that the environmental efficiencies in the east region are the highest, while those in the central region are the lowest. Thus far, China's domestic research on environmental efficiency has no unified definition. In fact, when studying the environmental efficiency of a certain industry, it is generally referred to as environmental efficiency, energy environmental efficiency, or ecological efficiency; or when studying and measuring the environmental efficiency of a certain area, it is called regional environmental efficiency or environmental regulatory efficiency. Other terms are environmental governance efficiency, environmental governance investment efficiency, and ecological civilization construction efficiency.

Studies have also adopted spatial panel econometrics to analyze the relationships among economic growth, environmental efficiency, and energy consumption. Results reveal that the ratios of direct to total elasticity and those of direct to total effect for capital, labor, and energy input variables are fixed (Song et al. [4]). Zhang and Choi [5] employed SBM-DEA to study the environmental efficiency of various provinces in China, presenting the results that most provinces have low energy efficiency, and that there are differences in environmental efficiency among regions. Chen and Jia [6] considered undesired output factors and combined the DEA method and the Slacks-based Measure (SBM) model to measure the environmental efficiency of Chinese industries from 2008 to 2012. Their results noted that, except for a few developed provinces, the environmental efficiency of Chinese industries is generally low. Wu et al. [7] utilized a two-stage DEA model to evaluate the environmental efficiency of undesired output and conducted empirical research on 30 provinces and cities in 8 regions of China. Their results showed the validity of the model and reflected the real conditions of the environment in eight regions.

Yao et al. [8] used panel data from China's provincial industrial sector from 1998 to 2011 and estimated the change in China's carbon dioxide emission efficiency and its driving forces according to the meta-frontier non-radial Malmquist $\mathrm{CO}_{2}$ emission performance index (MNMCPI). They found that the average carbon dioxide emissions of the industrial sector in the eastern, central, and western regions declined 5.53\% in total, sequentially. Castellet and Molinos-Senante [9] considered that each pollutant removed by a sewage treatment plant will have a different impact on the environment and used a weighted slacksbased measure model to measure the efficiency of the plant. Their analysis found that sewage treatment plants have a lot of room in terms of saving personnel and energy costs. Giovanna et al. [10] employed the approaches of AHP and NDDF to analyze the environmental treatment efficiency of 96 sewage treatment plants in Tuscany (Italy). Feng et al. [11] used the DDF model to analyze the wastewater treatment efficiency of 31 provinces and cities in China from 2011 to 2015. The results show that the wastewater treatment effect in economically developed areas is better, and the wastewater treatment efficiency in China needs to be improved. Considering energy saving, pollution treatment, and external environmental heterogeneity, Liu et al. [12] adopted a modified three-stage data envelopment analysis (DEA) model to evaluate the ecological efficiency of 30 provinces and cities in China in 2015, and the results indicate that economic development factors such as level, technological innovation, environmental regulation, and industrial structure have affected the ecological efficiency of various regions. Wu et al. [13] improved the DEA model to avoid non-homogeneous problems and used it to analyze the environmental performance of 38 industrial sectors in China for 5 years. The results show that the 
environmental performance of China's industrial sector is still low and uneven, but 38 industrial sectors. The overall efficiency keeps an upward trend. Zhang et al. [14] used the dynamic SBM method to analyze the environmental treatment efficiency of industrial water pollution in 30 provinces and cities in China from 2011 to 2015 . The study found that the efficiency of industrial water pollution treatment in 30 provinces and cities fluctuates, and the level of industrial output imbalance with industrial wastewater treatment performance. Wang and Feng [15] used a two-stage network-based super DEA approach to analyze the overall efficiency and ecological efficiency of China's industrial sector during the production phase and pollutant treatment phase. Their study found that the overall efficiency of the industrial sector significantly improved in the production phase and the wastewater treatment phase.

In terms of research methods, there are two main ones for evaluating production efficiency: SFA and DEA. SFA has statistical characteristics and can measure production efficiency and total factor productivity, but its general method cannot solve the common multi-output problem in actual production. DEA does not need to set the production function and weights in advance, can provide feasible suggestions for the improvement of invalid units, and can effectively deal with undesired output. A large number of studies and research results show that the DEA method is considered to be the best method for evaluating environmental efficiency and environmental governance efficiency (Song et al. [16], George et al. [17], Chang et al. [18], Lorenzo-Toja et al. [19]).

Farrell [16] applied the concept of the boundary production function to measure the production efficiency level of decision-making units. It connects the most efficient production points to the production boundary. Moreover, the gap between any real production point and the production boundary indicates the degree of inefficiency of the production point. Ever since Farrell [20] proposed the concept of efficiency boundary, it has been frequently used in various types of efficiency evaluation models.

Based on the concept of Farrell [20], Charnes et al. [21] extended their theory to establish a generalized mathematical linear programming model that can measure multiple inputs and multiple outputs of fixed returns to scale, calling it the CCR model. Both the CCR and Farrell models assume that all decision-making units are at fixed returns to scale. However, in actual situations, there may also be increasing returns to scale (IRS) or decreasing returns to scale (DRS). Therefore, Banker et al. [22] proposed the BCC model in 1984 and revised the fixed returns to scale assumption by the CCR model into variable returns to scale (VRS). Because the CCR model and the BCC model measure radial efficiency, they assume that input items or output items can increase or decrease in equal proportions, however, this assumption is not applicable in all situations. Therefore, Tone [23] proposed the Slack-Based Measure (SBM) in 2001, used the difference variable as the basis for measurement, considered the slack between the input and output items, and applied a non-radial estimation method and a single value (scalar) to present the SBM efficiency. The efficiency value is between 0 and 1. In addition to the above, DDF (Direction Distance Function) is a commonly used efficiency measurement tool when considering unintended output, because DDF can deal with reduced input and increased output at the same time.

Chung et al. [24] proposed the concept of the output-oriented distance function, which is an extended radial output distance function (RDF). The traditional DDF is a ray measurement mode, and the efficiency calculation fails to include all non-zero differences and all sources of inefficiency. Therefore, the efficiency value obtained will be overestimated. In order to solve this type of problem, Färe and Grosskopf [25] and Chen et al. [26] established a non-guided direction distance function. Compared to other methods, their function is better, because it provides more reasonable and accurate estimation results.

Traditional DEA mainly focuses on a static comparison when evaluating efficiency and lacks an evaluation and analysis of different time periods. The development of dynamic DEA window analysis, proposed by Kloop [27], was first used for dynamic analysis, but did not analyze the effect of carry-over activities between two periods. Fare and 
Grosskopf [28] were the first to use a carry-over variable in DEA analysis. Following Färe et al. [25], Tone and Tsutsui [29] extended the model to dynamic analysis of slack-based measures. Traditional DEA usually assumes that all producers have the same level of production technology when performing efficiency evaluations, but the decision-making units under evaluation often vary due to differences in geographical locations, national policies, and social and economic conditions. Thus, Battese and Rao [30], Battese et al. [31] and $\mathrm{O}^{\prime}$ Donnell et al. [32] set the common boundary as the concept of the meta-frontier and applied it to DEA efficiency estimation. The common boundary is estimated through all the group samples, and then the decision-making units are divided into groups. The group frontier of each group is estimated separately, and then the common boundary and the group are used. The distance value between group frontiers is used to evaluate whether the production technology level used by the group samples is close to the potential production technology level of the common boundary.

In summary, the evaluation index system and measurement methods of environmental efficiency and environmental pollution control efficiency are becoming more and more perfect. However, many scholars regard the decision-making unit (DMU) as a "black box" to measure the relative relationship between initial input and final output efficiency, ignoring the complexity of the DMUs' internal structure and leading them either only to look at the overall efficiency of energy and environment in the production process or only to study the efficiency of environmental governance investment in the pollution control process, thus lacking a systematic analysis of the two perspectives of energy utilization and pollution control. Existing studies have also generally investigated industrial environmental efficiency or environmental pollution control efficiency in a broad manner, and thus there is a lack of subdivided research on various sectors of industry. Performance evaluation based on the DDF non-ray distance function is better and can provide more reasonable and accurate estimation results. However, Fare et al. [25]'s DDF non-radial distance function fails to consider inter-period continuous effects and different production technologies. Therefore, our research combines Tone and Tsutsui [29]'s dynamic DEA and O'Donnell et al. [32]'s common boundary (meta-frontier) and proposes the meta Dynamic DDF model to measure the performance of China's wastewater treatment and to individually evaluate the technology gap.

\section{Model Selection and Research Methods}

\subsection{Meta Dynamic DDF Model}

Combining Tone and Tsutsui [29]'s dynamic DEA and O'Donnell et al. [32]'s metafrontier, we propose the meta Dynamic DDF model and construct it as follows.

The technology or production possibility set (PPS) is defined as the set of all pairs ( $x$, $y)$, where $\mathrm{x}$ is a vector of $\mathrm{m}$ inputs and a vector $\mathrm{y}$ of $\mathrm{s}$ outputs.

$$
\mathrm{L}(\mathrm{y})=\{(\mathrm{x}, \mathrm{y}) \mid \mathrm{x} \text { can produce } \mathrm{y}\}
$$

Considering the direction vector $\left(\mathrm{g}^{\mathrm{x}}, \mathrm{g}^{\mathrm{y}}\right)$ of each input and output $(\mathrm{x}, \mathrm{y})$, the direction distance function (DDF) is defined as follows:

$$
\mathrm{D}\left(\mathrm{x}_{\mathrm{j}}, \mathrm{y}_{\mathrm{j}}, \mathrm{g}^{\mathrm{x}}, \mathrm{g}^{\mathrm{y}}\right)=\sup \left\{\beta \mid\left(\mathrm{x}-\beta \mathrm{g}^{\mathrm{x}}, \mathrm{y}+\beta \mathrm{g}^{\mathrm{y}}\right) \in \mathrm{L}(\mathrm{y})\right\} \cdot\left(\mathrm{g}_{\mathrm{j}}^{\mathrm{x}}, \mathrm{g}_{\mathrm{j}}^{\mathrm{y}}\right)=\left(\mathrm{g}_{\mathrm{ij}}^{\mathrm{x}}, \ldots, \mathrm{g}_{\mathrm{mj}}^{\mathrm{x}}, \mathrm{g}_{\mathrm{ij}}^{\mathrm{y}}, \ldots, \mathrm{g}_{\mathrm{xj}}^{\mathrm{y}}\right)
$$

Here, $\widetilde{D}\left(x_{j}, y_{j}, g^{x}, g^{y}\right)$ is relative to the jth DMU, the input and output of $\operatorname{DMU}_{j}\left(x_{j}, y_{j}\right)$. According to the above direction distance function, we then introduce the dynamic and common boundary (meta-frontier) architecture, which is the meta Dynamic DDF model. Its model description runs as follows.

\section{(1) Meta-frontier (MF)}

We first assume that due to differences in management types, resources, regulations, or environments that all manufacturers are composed of DMUs in groups-namely, ( $N=$ $\left.N_{1}+N_{2}+\ldots+N_{G}\right)$. We then assume that the DMU exists in each time $t$, where $t=1$, $\ldots, \mathrm{T}$. In each time period, $D U M_{m}$ inputs $x_{i j}^{t}(i=1, \ldots, m)$ produce $K_{1}$ desirable outputs 
$q_{k j}^{d^{t}}\left(k=1, \ldots, K_{2}\right)$ and $K_{2}$ undesirable outputs $q_{k j}^{u^{t}}\left(k=1, \ldots, K_{2}\right)$, and $Z_{d j}^{t}(d=1, \ldots, \mathrm{D})$ is the carryover variable. Under the common boundary, the DMU can choose the most favorable final output weight to maximize its efficiency value. Therefore, the efficiency of DMU $k$ under the common boundary can be solved by the following linear programming procedure.

The efficiency of DMUs is:

$\max \theta^{* *}$

s.t.

$\sum_{g=1}^{G} \sum_{j=1}^{n} \lambda_{g j}^{t} x_{g i j}^{t} \leq x_{i p}^{t}-\theta_{1}^{t} R_{i p}^{x, t} \forall i, \forall t$

$\sum_{g=1}^{G} \sum_{j=1}^{n} \lambda_{g j}^{t} z_{g d j}^{t} \leq z_{d p}^{t}-\theta_{1}^{t} R_{d p}^{Z, t} \forall d, \forall t$

$\sum_{g=1}^{G} \sum_{j=1}^{n} \lambda_{g j}^{t} q_{g k j}^{d^{t}} \geq q_{k}^{d^{t}}+\theta_{1}^{t} R_{k p}^{q^{d} t} \forall k, \forall t$

$\sum_{g=1}^{G} \sum_{j=1}^{n} \lambda_{g j}^{t} q_{g k j}^{u^{t}} \leq q_{k}^{u^{t}}-\theta_{1}^{t} R_{k p}^{q^{u} t} \forall k, \forall t$

$\sum_{g=1}^{G} \sum_{j=1}^{n} \lambda_{g j}^{t-1} z_{g d j}^{t}=\sum_{g=1}^{G} \sum_{j=1}^{n} \lambda_{g j}^{t} z_{g d j}^{t}$

$\sum_{g=1}^{G} \sum_{j=1}^{n} \lambda_{g j}^{t}=1 \forall t$

$\lambda_{j}^{t} \geq 0 \forall i, \forall t$

Total efficiency is $\theta^{* *}=\sum_{t=1}^{T} \gamma_{t} \rho^{t}$, where $\rho^{t}$ stands for period efficiencies, and $\gamma_{t}$ is the weight assigned to period $t$. For each $t, \gamma_{t} \geq 1$ and $\sum_{t=1}^{T} \gamma_{t}=1$.

(2) Group-frontier (GF)

The efficiency of the decision-making unit is:

$\max \theta^{* g}$

$\sum_{j=1}^{\text {s.t. }} \lambda_{j}^{t} x_{i j}^{t} \leq x_{i p}^{t}-\theta_{1}^{t} R_{i p}^{x, t} \forall i, \forall t$

$\sum_{j=1}^{n} \lambda_{j}^{t} z_{d j}^{t} \leq z_{d p}^{t}-\theta_{1}^{t} R_{d p}^{Z, t} \forall d, \forall t$

$\sum_{j=1}^{n} \lambda_{j}^{t} q_{k j}^{d^{t}} \geq q_{k}^{d^{t}}+\theta_{1}^{t} R_{k p}^{q^{d} t} \forall k, \forall t$

$\sum_{j=1}^{n} \lambda_{j}^{t} q_{k j}^{u^{t}} \leq q_{k}^{u^{t}}-\theta_{1}^{t} R_{k p}^{q^{u} t} \forall k, \forall t$

$\sum_{j=1}^{n} \lambda_{j}^{t-1} z_{d j}^{t}=\sum_{j=1}^{n} \lambda_{j}^{t} z_{d j}^{t}$

$\sum_{j=1}^{n} \lambda_{j}^{t}=1 \forall t$

$\lambda_{j}^{t} \geq 0 \forall i, \forall t$

(3) Technology gap ratio (TGR)

The production frontiers of the g groups are included in the meta-frontier. The technical efficiency under the meta-frontier must be less than the technical efficiency under the group frontier. The ratio of the two frontiers is called the Technology Gap Ratio (TGR): $\mathrm{TGR}=\frac{\theta^{* *}}{\theta^{* g}}$

\subsection{Input, Desirable Output, and Undesirable Output Efficiencies}

Hu and Wang's [33] total-factor energy efficiency index can be used to overcome any possible biases in the traditional energy efficiency indicators. There are five key efficiency 
models: energy consumed, GDP, Wastewater, Waste Gas, and Waste Solid, where "I" represents area and " $\mathrm{t}$ " represents time. The efficiency models are therefore:

$$
\begin{aligned}
\text { Input efficiency } & =\frac{\text { Target input }}{\text { Actual input }} \\
\text { Undesirable output efficiency } & =\frac{\text { Target Undesirable output }}{\text { Actual Undesirable output }} \\
\text { Desirable output efficiency } & =\frac{\text { Actual Desirable output }}{\text { Target Desirable output }}
\end{aligned}
$$

If the target inputs and undesirable outputs equal the actual inputs and undesirable outputs, then the efficiencies are 1 , which indicate overall efficiency. However, if the target inputs and undesirable outputs were less than the actual inputs and undesirable outputs, then the efficiencies were less than 1 , which indicated overall inefficiency.

If the target desirable outputs are equal to the actual desirable outputs, then the efficiencies are 1, indicating overall efficiency. However, if the target desirable outputs are more than the actual desirable outputs, then the efficiencies are less than 1, indicating overall inefficiency.

\section{Data Processing and Analysis of Empirical Results}

\subsection{Data and Variables}

From past research on energy and environment, the inputs are generally labor, fixed assets, and energy consumption, such as in $\mathrm{Hu}$ and Wang [33], Li et al. [34], Wang and Wei [35], and Du et al. [36]. Outputs are mainly GDP, $\mathrm{CO}_{2}$, and $\mathrm{SO}_{2}$, such as in $\mathrm{Li}$ et al. [34], Wang and Wei [35] and Wang et al. [37]. This study utilizes panel data from 30 provinces in China. Traditional research has divided China into eastern, central, and western regions based on geographical location, but these classifications do not directly reflect production technology level variations. Therefore, based on the World Bank's classification for rich and poor countries, we divide the 30 provinces into high-income cities and upper-middleincome cities, with the upper-middle-income economies' GNI per capita between $\$ 3896$ and $\$ 12,055$ and the high-income economies' GNI per capita at $\$ 12,056$ or more. The high-income cities are Beijing, Shanghai, Tianjin, Jiangsu, Zhejiang, Fujian, Guangdong, Shandong, Inner Mongolia, Chongqing, Hubei, Shaanxi, Jilin, and Liaoning (14 provinces in total). The upper-middle income cities are Niaoning, Ningxia, Hunan, Hainan, Henan, Hebei, Xinjiang, Sichuan, Qinghai, Jiangxi, Anhui, Shanxi, Heilongiang, Guangxi, Guizhou, Yunnan, and Gansu (16 provinces in total). Among the 14 provinces and cities in the high-income group, 9 are provinces in the eastern region, 3 are provinces in the central region, and 2 are provinces in the western region. This is basically in line with the current situation of China's regional economic development, that is, the eastern region is relatively developed and the central and western regions are relatively backward.

We extract the data for 2010 to 2017 from the Statistical Yearbook of China, the Demographics and Employment Statistical Yearbook of China, and the Statistical Yearbooks from each province. Figure 1 reveals the framework of the Network Dynamic Model of inter-temporal efficiency measurement and the variables (see Table 1). 


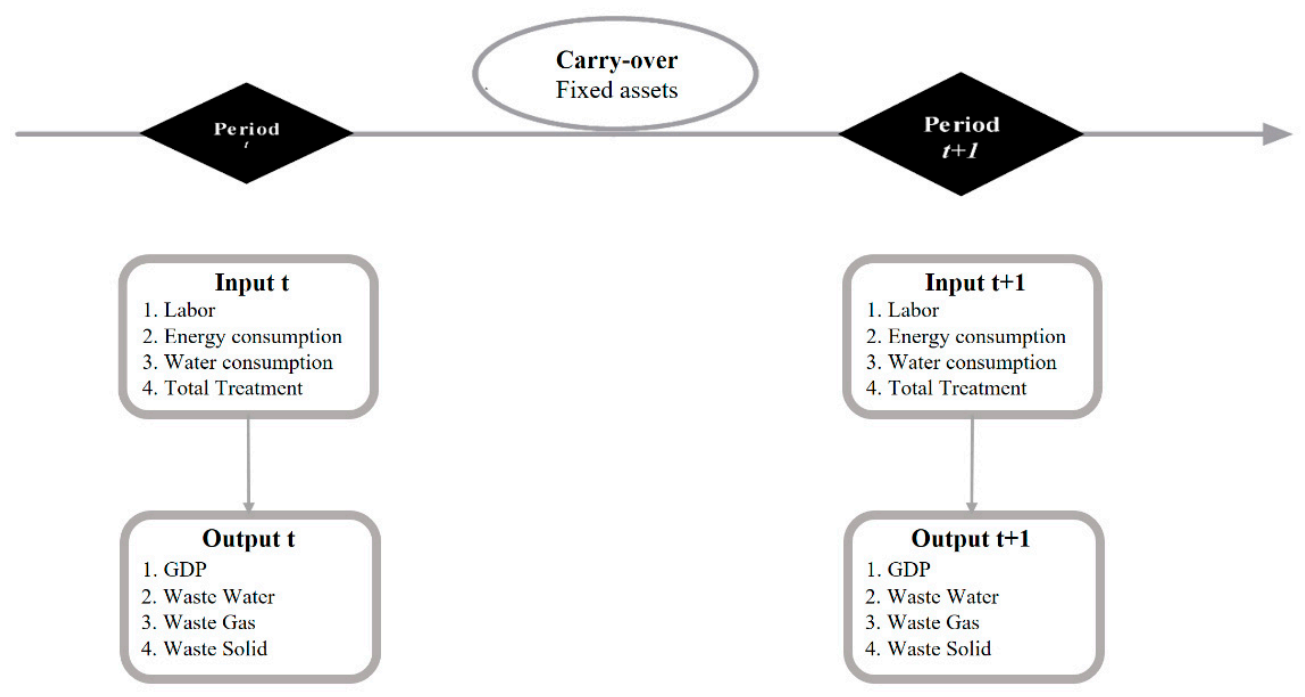

Figure 1. Model Framework.

Table 1. Input and output variables.

\begin{tabular}{cccc}
\hline \multirow{2}{*}{ Input Variables } & \multicolumn{2}{c}{ Output Variables } & \multirow{2}{*}{ Carry-Over } \\
\cline { 2 - 3 } & $\begin{array}{c}\text { Desirable Output } \\
\text { Variables }\end{array}$ & $\begin{array}{c}\text { Undesirable Output } \\
\text { Variables }\end{array}$ & \\
\hline Labor & Wastewater & \\
$\begin{array}{c}\text { Energy consumption } \\
\text { Water consumption } \\
\text { Total treatment }\end{array}$ & GDP & Waste gas & Waste solid \\
(Data source: Authors' collection). & & & \\
\hline
\end{tabular}

Table 2 lists the basic statistics of various input and output indicators for the highincome and upper-middle-income groups. In the high-income group, water consumption in the input elements, waste gas emissions in the undesired output elements, and solid waste emissions are all lower than the upper-middle-income group. Moreover, the average values of the other input factors and output factors in the high-income group are higher than those of the upper-middle-income group. 
Table 2. Descriptive statistical analysis.

\begin{tabular}{|c|c|c|c|c|c|c|c|c|c|c|c|}
\hline \multirow{2}{*}{\multicolumn{2}{|c|}{ Variable/Cluster }} & \multicolumn{5}{|c|}{ High-Income } & \multicolumn{5}{|c|}{ Upper-Middle-Income } \\
\hline & & \multirow{2}{*}{$\begin{array}{c}\text { Mean } \\
2822.85\end{array}$} & \multirow{2}{*}{$\begin{array}{c}\text { Std. Dev. } \\
1814.76\end{array}$} & \multirow{2}{*}{$\begin{array}{c}\text { Min } \\
728.70\end{array}$} & \multirow{2}{*}{$\begin{array}{c}\text { Max } \\
6649.70\end{array}$} & \multirow{2}{*}{$\begin{array}{c}\text { Observations } \\
\mathrm{N}=112\end{array}$} & \multirow{2}{*}{$\begin{array}{c}\text { Mean } \\
2594.25\end{array}$} & \multirow{2}{*}{$\begin{array}{c}\text { Std. Dev. } \\
1709.52\end{array}$} & \multirow{2}{*}{$\begin{array}{c}\text { Min } \\
307.65\end{array}$} & \multirow{2}{*}{$\begin{array}{c}\text { Max } \\
6767.00\end{array}$} & \multirow{2}{*}{$\begin{array}{c}\text { Observations } \\
\mathrm{N}=128\end{array}$} \\
\hline labor & overall & & & & & & & & & & \\
\hline energy e & overall & $16,854.60$ & 9250.79 & 6724.00 & $38,899.00$ & $\mathrm{~N}=112$ & $12,372.38$ & 7260.36 & 1359.00 & $30,385.8$ & $\mathrm{~N}=128$ \\
\hline asset & overall & $18,175.94$ & $11,927.56$ & 4962.10 & $55,202.70$ & $\mathrm{~N}=112$ & $12,824.70$ & 9326.52 & 1016.90 & $44,496.9$ & $\mathrm{~N}=128$ \\
\hline wuse & overall & 194.21 & 149.06 & 22.50 & 591.30 & $\mathrm{~N}=112$ & 208.18 & 138.06 & 25.80 & 590.14 & $\mathrm{~N}=128$ \\
\hline treatm & overall & $291,773.90$ & $258,105.2$ & $10,946.00$ & $1,416,464.00$ & $\mathrm{~N}=112$ & $172,705.50$ & $144,347.30$ & 4354.00 & 889,518 & $\mathrm{~N}=128$ \\
\hline gdp & overall & $29,705.55$ & $19,552.42$ & 7925.60 & $89,705.23$ & $\mathrm{~N}=112$ & $14,608.28$ & $10,119.09$ & 1350.40 & $44,552.8$ & $\mathrm{~N}=128$ \\
\hline wastew $\sim \mathrm{r}$ & overall & $294,562.10$ & $217,446.6$ & $67,147.00$ & $938,261.00$ & $\mathrm{~N}=112$ & $173,096.30$ & $113,206.40$ & $21,292.00$ & 433,487 & $\mathrm{~N}=128$ \\
\hline Waste gas & overall & 157.45 & 106.17 & 16.38 & 440.15 & $\mathrm{~N}=112$ & 159.45 & 100.99 & 4.35 & 453.57 & $\mathrm{~N}=128$ \\
\hline wastes d & overall & 8906.86 & 8194.64 & 629.00 & $32,434.00$ & $\mathrm{~N}=112$ & $11,823.75$ & 9574.15 & 212.00 & $45,575.8$ & $\mathrm{~N}=128$ \\
\hline
\end{tabular}

(Data source: Authors' collection). 


\subsection{Analysis of the Production Efficiency of Various Factors}

\subsubsection{Labor Efficiency}

From 2010 to 2017 (see Figure 2), the average labor efficiency in China has shown an upward trend, from 0.6129 to 0.6988 , and the allocation of labor resources has been continuously optimized. The average labor efficiency of the high-income groups in each year is higher than the national average labor efficiency, while the average labor efficiencies of the upper-middle-income groups are lower than the national average labor efficiency.

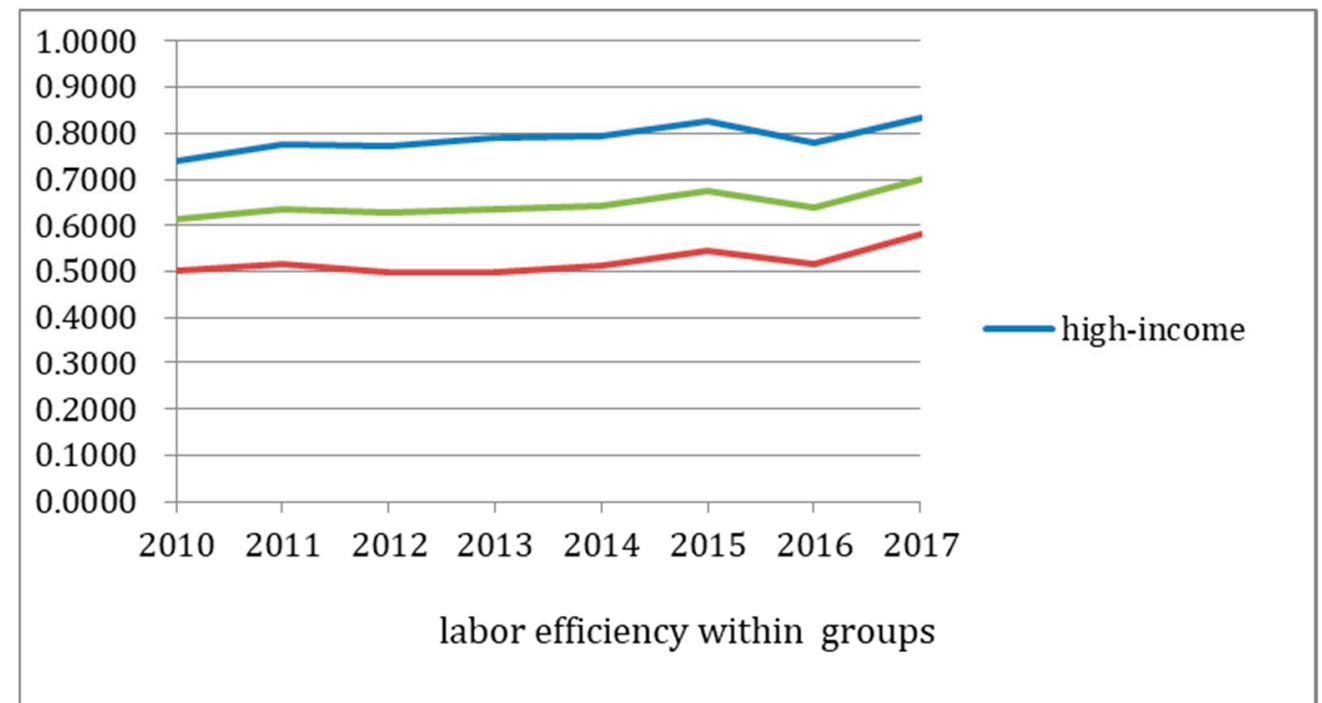

Figure 2. Average labor efficiency of each group from 2010 to 2017. (Data source: Authors' collection).

The labor efficiency of the provinces of China's high-income groups has shown an increasing trend, from 0.7410 in 2010 to 0.833 in 2017. Among them, the labor efficiencies of Beijing, Tianjin, and Shanghai are all 1 in the 8 years, thus realizing effective allocation of labor resources. The labor efficiencies of Inner Mongolia and Fujian have declined slightly, while the labor efficiencies of nine provinces, including Liaoning, Jilin, Jiangsu, Zhejiang, Shandong, Hubei, Guangdong, Chongqing, and Shaanxi, show an upward trend.

The labor efficiencies of China's upper-middle-income groups have also shown an increasing trend, from 0.5008 in 2010 to 0.5812 in 2017. Among them, Hainan has a labor efficiency of 1 in all 8 years, thus achieving effective allocation of labor resources. The labor efficiencies of five provinces including Hebei, Shanxi, Qinghai, Ningxia, and Xinjiang have declined slightly, and the labor efficiencies of nine provinces including Heilongjiang, Anhui, Jiangxi, Henan, Hunan, Guangxi, Sichuan, Guizhou, Yunnan, and Gansu have shown an upward trend.

\subsubsection{Energy Consumption Efficiency}

From 2010 to 2017 (see Figure 3), China's average energy consumption efficiency presents a downward trend, from 0.7727 to 0.6957 . The average energy consumption efficiency of the high-income groups in each year is higher than the national average energy consumption efficiency. However, the average energy consumption efficiencies of the upper-middle-income groups are lower than the national average energy consumption efficiency.

The energy consumption efficiencies of provinces in China's high-income groups have shown a downward trend, from 0.8829 in 2010 to 0.8094 in 2017. Among them, the energy consumption efficiencies of Beijing, Tianjin, and Shanghai are 1 in all 8 years, thus realizing the effective use of energy. The energy consumption efficiencies of eight provinces including Inner Mongolia, Liaoning, Jilin, Jiangsu, Zhejiang, Fujian, Shandong, and Shaanxi have declined slightly, while the energy consumption efficiencies of three provinces including Hubei, Guangdong, and Chongqing have an upward trend. 


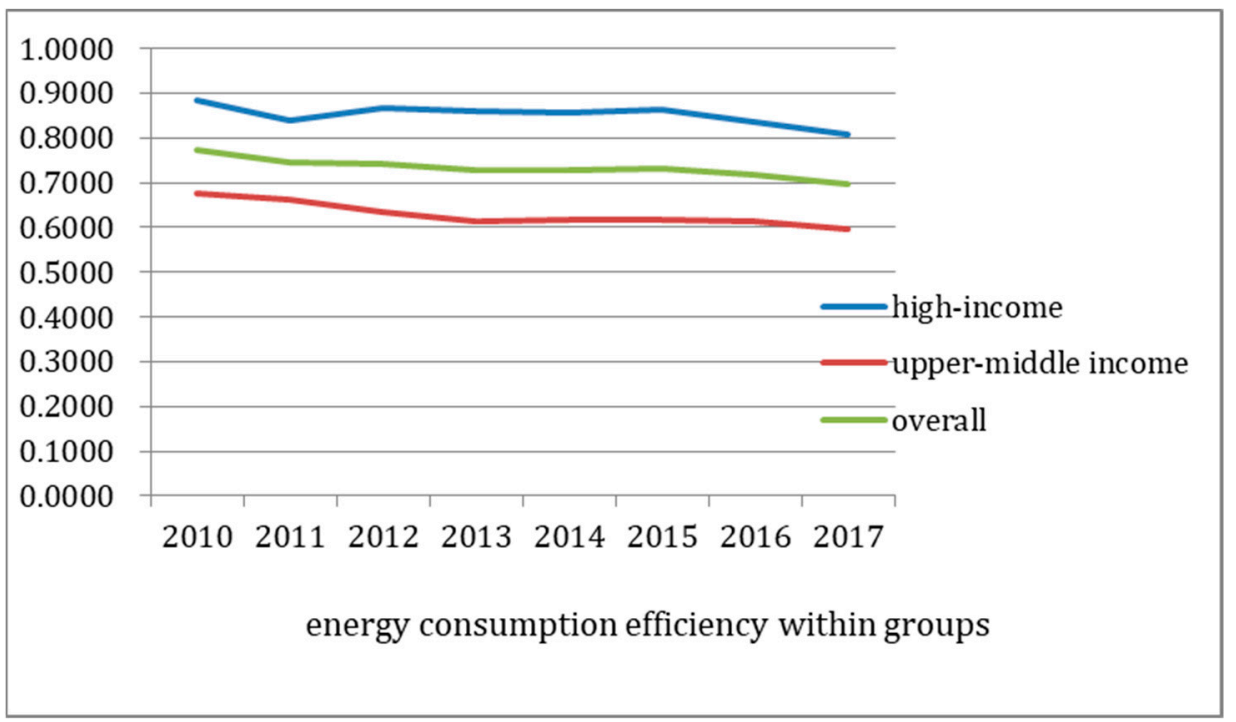

Figure 3. Average energy cons (Data source: Authors' collection).

The energy consumption efficiencies of provinces in China's upper-middle-income groups have also shown a downward trend, from 0.6763 in 2010 to 0.5962 in 2017. Among them, Hunan and Hainan both have energy consumption efficiency of 1 in all 8 years, thus hitting effective use of energy. The energy efficiencies of 13 provinces including Hebei, Shanxi, Inner Mongolia, Anhui, Jiangxi, Henan, Guangxi, Yunnan, Gansu, Qinghai, Ningxia, and Xinjiang have declined, while the energy consumption efficiencies of two provinces including Sichuan and Guizhou have an upward trend.

\subsubsection{Water Efficiency}

From 2010 to 2017 (see Figure 4), China's average water use efficiency has shown an upward trend, rising from 0.4982 to 0.5865 . The average water efficiency of the highincome groups in each year is higher than the national average water efficiency. However, the average water efficiencies of the middle- and high-income groups are lower than the national average.

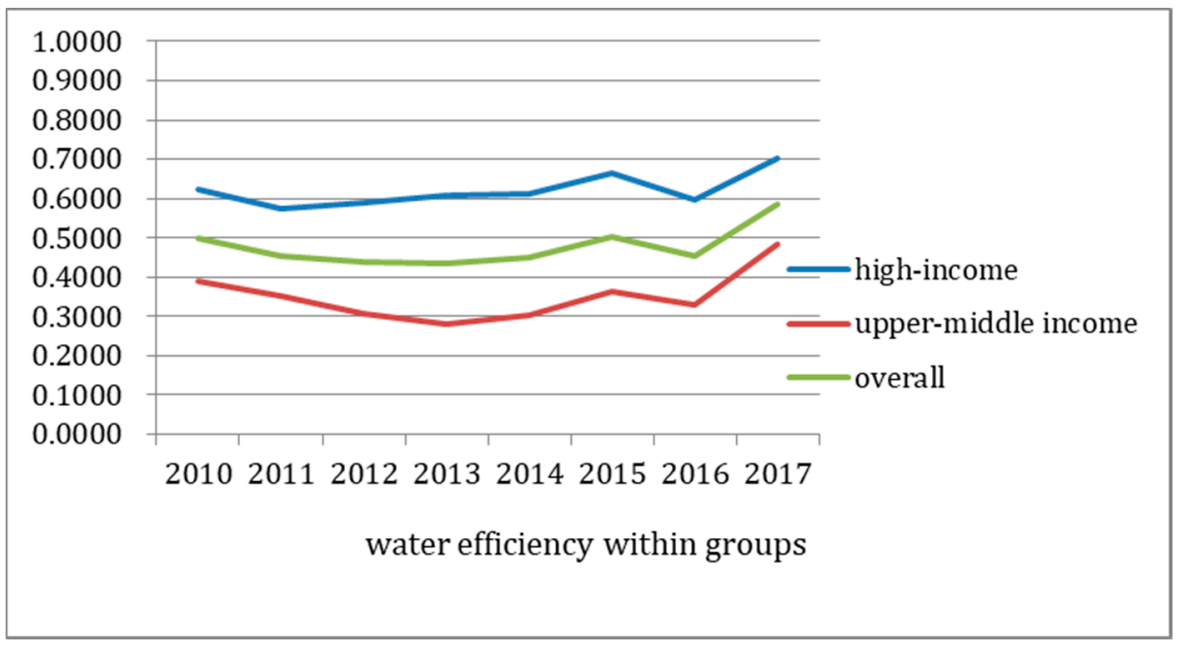

Figure 4. Average water efficiency of each group from 2010 to 2017. (Data source: Authors' collection).

The water use efficiencies of provinces in China's high-income groups have shown an upward trend, from 0.6232 in 2010 to 0.7021 in 2017. Among them, Beijing and Tianjin have water use efficiency of 1 in all 8 years, realizing effective use of water resources. The 
water use efficiencies of 6 provinces including Inner Mongolia, Jilin, Jiangsu, Fujian, Shandong, and Hubei have declined slightly, while the water use efficiencies of five provinces including Liaoning, Zhejiang, Guangdong, Chongqing, and Shaanxi have illustrated an upward trend.

The water use efficiencies of provinces in China's upper-middle-income groups have also shown an upward trend, from 0.3887 in 2010 to 0.4853 in 2017. Among them, Hainan has water use efficiency of 1 for all 8 years, thus achieving the effective use of water resources. The water use efficiencies of six provinces including Hebei, Shanxi, Anhui, Henan, Ningxia, and Xinjiang have declined, while the water use efficiencies of nine provinces including Heilongiiang, Jiangxi, Hunan, Guangxi, Sichuan, Guizhou, Yunnan, Gansu, and Qinghai have shown an upward trend.

\subsubsection{Investment Efficiency of Pollution Control}

From 2010 to 2017 (see Figure 5), the average investment efficiency of China's industrial pollution control has shown an upward trend, rising from 0.6962 to 0.8795 . The average investment efficiency of industrial pollution control for the high-income groups is higher than the average pollution control investment efficiency of the middle- and high-income groups. Moreover, the investment efficiencies of industrial pollution control for the middle-high-income groups are lower than the national average pollution control investment efficiency.

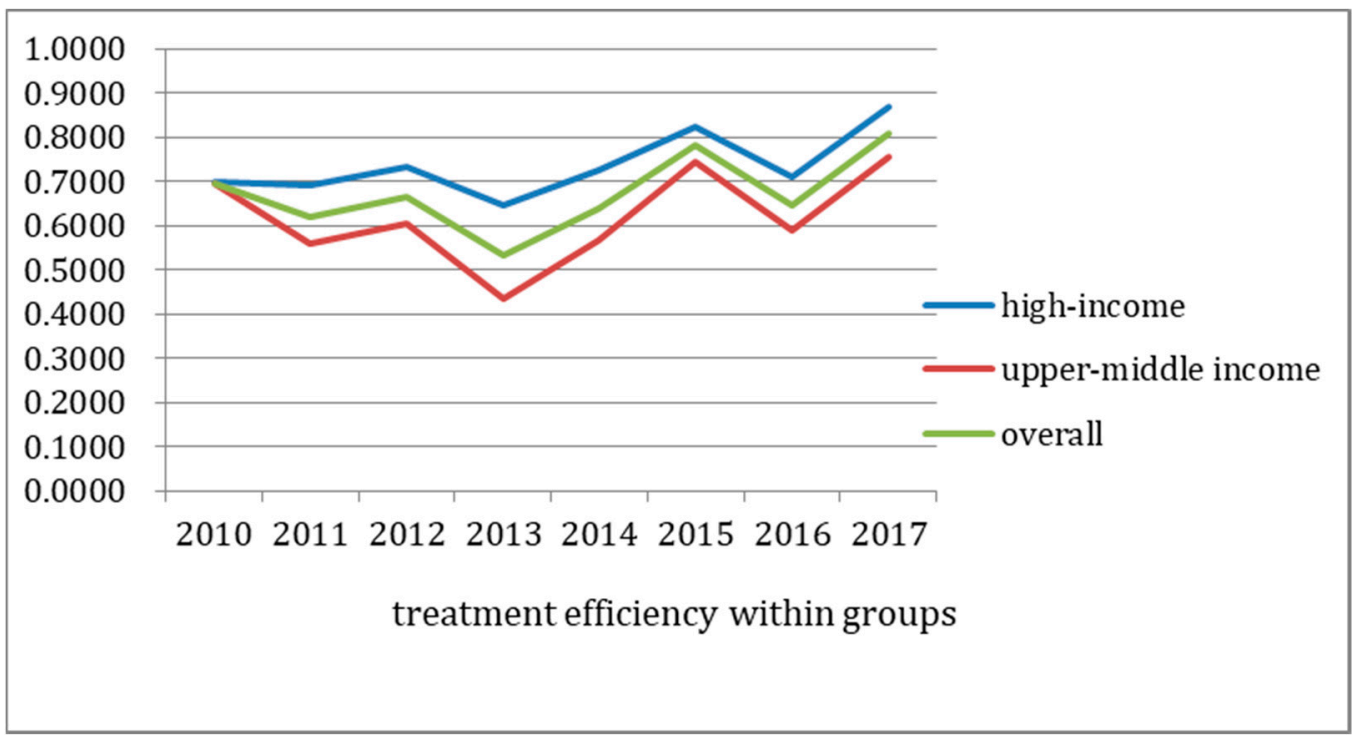

Figure 5. Average treatment efficiency of each group from 2010 to 2017. (Data source: Authors' collection).

The investment efficiencies of industrial pollution control in the provinces of China's high-income groups have shown an upward trend, from 0.6979 in 2010 to 0.8698 in 2017. Among them, the investment efficiencies of industrial pollution control in Beijing, Tianjin, and Shanghai are 1 in all 8 years, realizing the effective allocation of industrial pollution control investment. The investment efficiencies of industrial pollution control in Inner Mongolia and Shandong declined slightly, while the investment efficiencies of industrial pollution control in eight places including Liaoning, Jilin, Jiangsu, Zhejiang, Fujian, Hubei, Guangdong, and Chongqing have an upward trend.

The investment efficiencies of industrial pollution control in China's upper-middleincome groups have also shown an upward trend, from 0.6947 in 2010 to 0.7538 in 2017. Among them, the investment efficiency of Hainan's industrial pollution control in all 8 years is 1 , as it has been able to effectively realize pollution control. The investment efficiencies of industrial pollution control in seven provinces including Hebei, Shanxi, 
Inner Mongolia, Anhui, Henan, Ningxia, and Xinjiang have declined, while investment in industrial pollution control in eight provinces including Jiangxi, Hunan, Guangxi, Sichuan, Guizhou, Yunnan, Gansu, and Qinghai Efficiency is on the rise.

\subsubsection{GDP Efficiency}

From 2010 to 2017 (see Figure 6), China's GDP efficiency average has shown an upward trend, rising from 0.8700 to 0.9149 . The average GDP efficiency of the high-income group in each year is higher than the average GDP efficiency of the national and uppermiddle-income groups. Contrarily, the GDP efficiency of the upper-middle-income group is lower than the national average GDP efficiency.

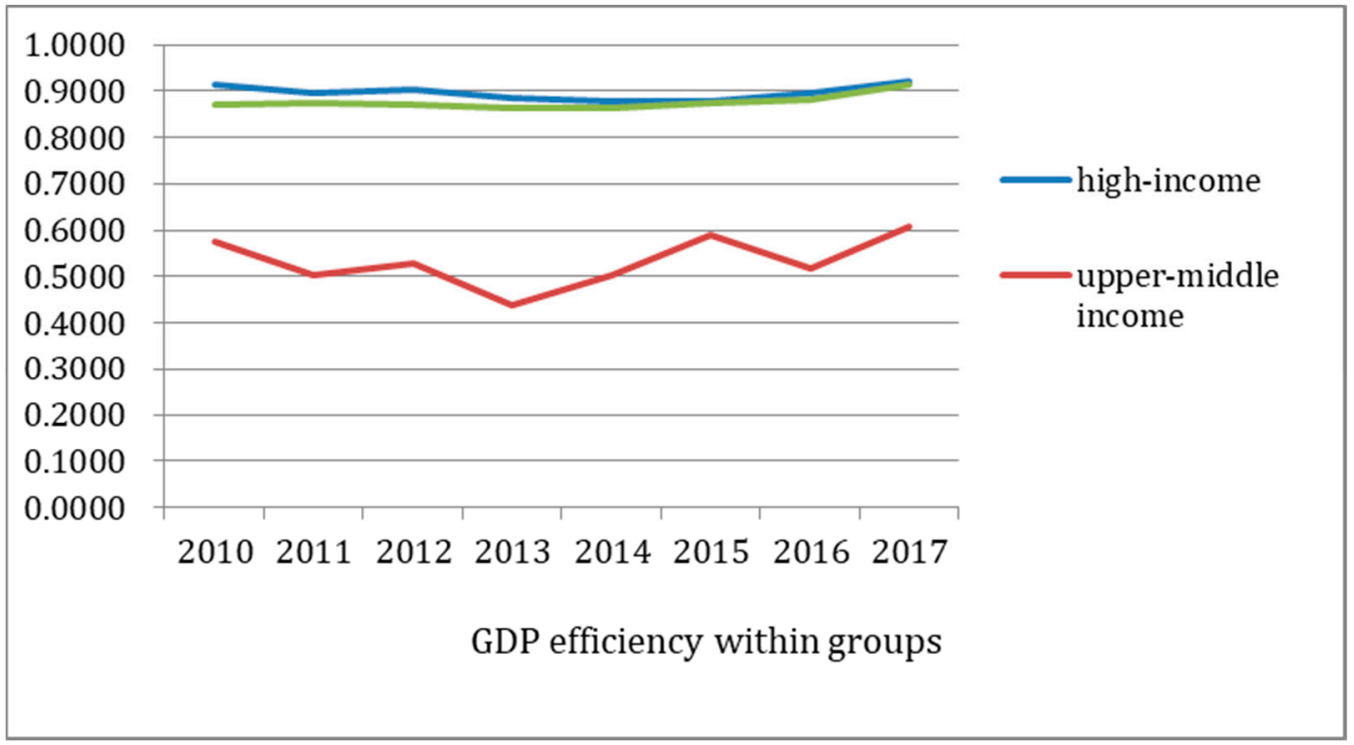

Figure 6. Average GDP efficiency of each group from 2010 to 2017. (Data source: Authors' collection).

The GDP efficiencies of provinces in China's high-income groups have shown an upward trend, rising from 0.9127 in 2010 to 0.9220 in 2017. Among them, the GDP efficiencies of Beijing, Tianjin, and Fujian are 1 in all 8 years, achieving optimal output. The investment efficiencies of industrial pollution control in Inner Mongolia, Liaoning, Jilin, Zhejiang, Hubei, and Guangdong have declined slightly, while the GDP efficiencies in Shanghai, Jiangsu, Shandong, Chongqing, and Shaanxi have shown an upward trend.

The GDP efficiencies of provinces in China's upper-middle-income groups have also shown an upward trend, rising from 0.8326 in 2010 to 0.9086 in 2017. Among them, GDP efficiencies of Hunan's industrial pollution control in all 8 years is 1 , thus effectively realizing optimal output. The GDP efficiencies of four provinces including Hebei, Shanxi, Yunnan, and Gansu have declined. The GDP efficiencies of 11 provinces including Heilongjiang, Anhui, Jiangxi, Henan, Hunan, Guangxi, Hainan, Sichuan, Guizhou, Qinghai, and Ningxia have shown an upward trend.

\subsubsection{Wastewater Efficiency}

From 2010 to 2017 (see Figure 7), the average wastewater treatment efficiency in China has shown an upward trend, rising from 0.8139 to 0.8641 . The average waste gas treatment efficiencies of the high-income groups are higher than the average wastewater treatment efficiencies of the middle- and high-income groups. Moreover, the wastewater treatment efficiencies of the upper-middle-income groups are all lower than the national average wastewater treatment efficiency. 


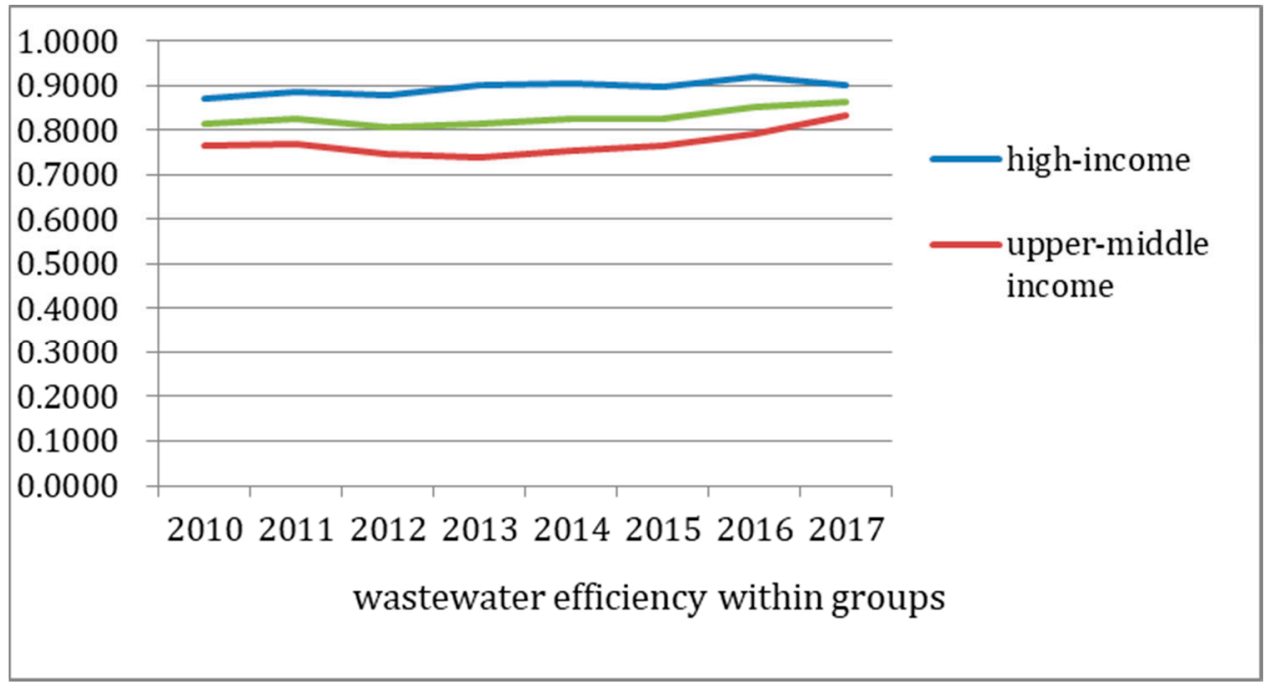

Figure 7. Average wastewater efficiency of each group from 2010 to 2017. (Data source: Authors' collection).

The efficiencies of wastewater treatment in various provinces of China's high-income groups have shown an upward trend, from 0.8712 in 2010 to 0.9011 in 2017. Among them, the wastewater treatment efficiencies of Beijing, Tianjin, and Shanghai are 1 in all 8 years, realizing effective wastewater treatment. The efficiencies of wastewater pollution treatment in four provinces including Inner Mongolia, Liaoning, Shandong, and Shaanxi have declined slightly. Conversely, the efficiencies of wastewater pollution treatment in eight places including Jilin, Shanghai, Jiangsu, Zhejiang, Fujian, Hubei, Guangdong, and Chongqing have shown an upward trend.

The efficiencies of wastewater treatment in various provinces in China's upper-middleincome groups have also shown an upward trend, from 0.7638 in 2010 to 0.8316 in 2017. Among them, Hainan's wastewater treatment efficiency is 1 in all 8 years, realizing effective waste water treatment. The efficiencies of wastewater pollution treatment in seven provinces including Hebei, Shanxi, Heilongjiang, Anhui, Henan, Gansu and Xinjiang have declined, while the efficiencies of wastewater treatment in eight provinces including Jiangxi, Hunan, Guangxi, Sichuan, Guizhou, Yunnan, Qinghai, and Ningxia have an increasing trend.

\subsubsection{Waste Gas Efficiency}

From 2010 to 2017 (see Figure 8), the average value of China's waste gas treatment efficiency has a downward trend, from 0.5014 to 0.4952 . The average exhaust gas treatment efficiencies of the high-income groups are higher than the average exhaust gas treatment efficiencies of the upper-middle-income groups. Moreover, the exhaust gas treatment efficiencies of the upper-middle-income groups are all lower than the national average exhaust gas treatment efficiency.

The exhaust gas treatment efficiencies of various provinces in China's high-income groups have shown an upward trend, from 0.6255 in 2010 to 0.6493 in 2017. Among them, the exhaust gas treatment efficiencies of Beijing, Tianjin, and Fujian are 1 in all 8 years, realizing effective exhaust gas treatment. Inner Mongolia, Liaoning, Jilin, Shandong, and other four provinces have a slight decline in their efficiency of waste gas pollution control, while the efficiencies of waste gas pollution control in six places including Zhejiang, Fujian, Hubei, Guangdong, Chongqing, and Shaanxi have shown an upward trend. 


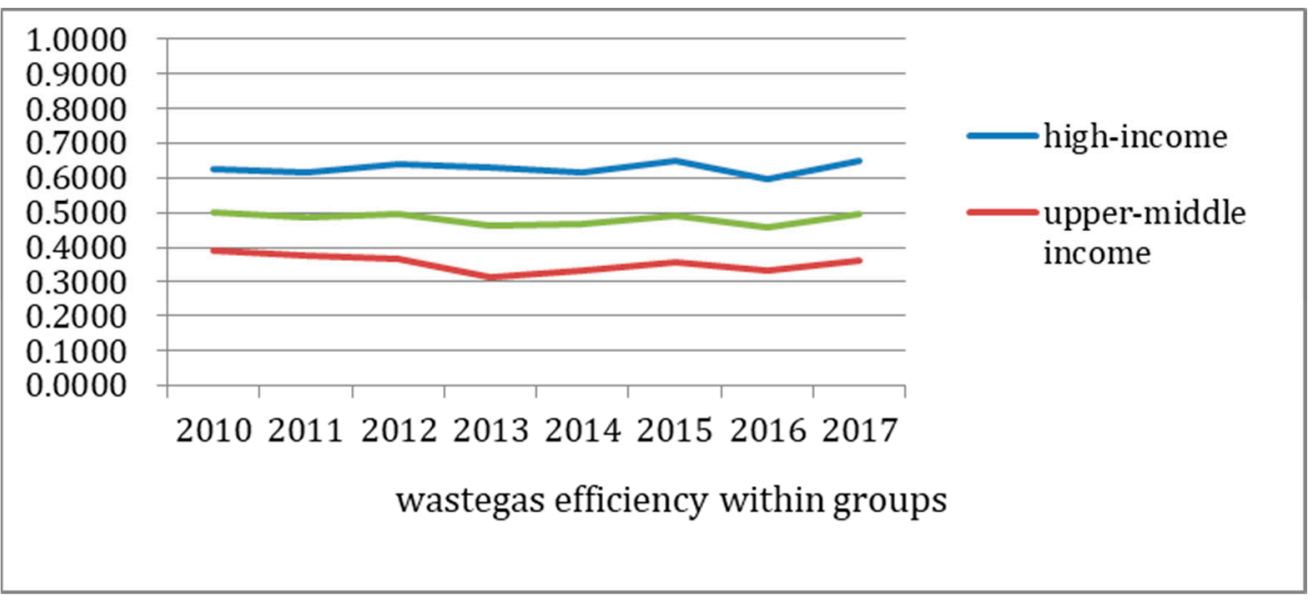

Figure 8. Average waste gas efficiency of each group from 2010 to 2017. (Data source: Authors' collection).

The efficiencies of waste gas treatment in China's upper-middle-income groups have shown a downward trend, from 0.3928 in 2010 to 0.3604 to 2017. Among them, Hainan's waste gas treatment efficiency is 1 for all 8 years, realizing effective waste gas treatment. The treatment efficiencies of waste gas pollution in seven provinces including Hebei, Heilongjiang, Anhui, Yunnan, Qinghai, Ningxia, and Xinjiang have declined, while the treatment efficiencies of industrial waste gas in eight provinces including Shanxi, Jiangxi, Henan, Hunan, Guangxi, Sichuan, Guizhou, and Gansu have an upward trend.

\subsubsection{Waste Solid Efficiency}

From 2010 to 2017 (see Figure 9), the average value of China's solid waste treatment efficiency exhibits a downward trend, from 0.5014 to 0.3619 . The average solid waste treatment efficiency of the high-income groups in each year is higher than the average solid waste treatment efficiency of the country and the upper-middle-income groups, and the solid waste treatment efficiencies of the middle- and high-income groups are all lower than the national average solid waste treatment efficiency.

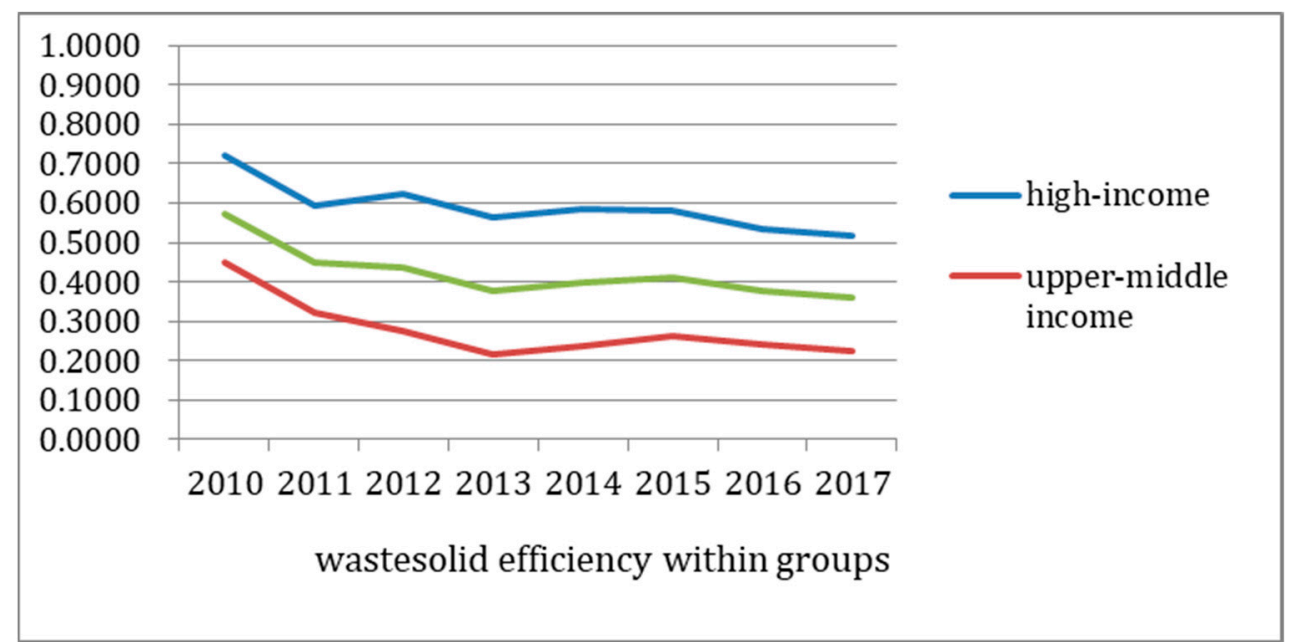

Figure 9. Average waste solid efficiency of each group from 2010 to 2017. (Data source: Authors' collection).

The efficiencies of solid waste treatment in the provinces of China's high-income groups have shown a downward trend, from 0.7198 in 2010 to 0.5167 in 2017. Among them, the efficiencies of solid waste treatment in Beijing, Tianjin, and Shanghai are 1 in all 
8 years, realizing effective treatment of solid waste. The efficiencies of solid waste pollution control in nine provinces including Inner Mongolia, Liaoning, Jilin, Jiangsu, Zhejiang, Fujian, Shandong, Hubei, and Shaanxi show a downward trend, while the efficiencies of solid waste pollution control in Guangdong and Chongqing show an upward trend.

The efficiencies of solid waste treatment in various provinces in China's upper-middleincome groups also show a downward trend, from 0.4475 in 2010 to 0.2264 to 2017. Among them, Hainan has achieved solid waste treatment efficiency of 1 , which denotes effective treatment. With the exception of Hunan's solid waste treatment efficiency showing an upward trend, other provinces and cities have shown a downward trend.

The above results show that after considering energy input and pollution control, in the environmental pollution control of China's industrial sector, the level of sewage treatment is generally on the rise, and the high-income group is higher than the highincome group. This is in line with the existing research of Wang and Feng [15]. The research conclusions of Song et al. [16] are basically the same. The slight difference is that the research in this article found that the efficiency of waste gas treatment and solid waste treatment in China's industrial sector showed a downward trend during 2010-2017, while Wang and Feng [15] found that the governance levels of the two were not improved significantly during 2004-2015. The difference in the research results may lie in the selection of the research period, and the efficiency of the allocation of elements during the period has not yet appeared. Air pollution is one of the most concerning environmental pollution problems in Chinese society in recent years. During 2013-2017, only the central air pollution prevention and control special funds were allocated 5 billion yuan, 9.8 billion yuan, 10.6 billion yuan, 11.18 billion yuan and 16 billion yuan, respectively, showing an increasing trend year by year. At the same time, there are problems in air pollution prevention such as insufficient matching of fund use with key prevention and control tasks, and lagging progress in fund implementation.

\subsection{Analysis of Meta Technical Efficiency and Group Technical Efficiency}

We adopt the meta frontier method to construct the production frontier with the input-output data of all years of the decision-making units. The calculation results appear in Table 3.

Under the meta frontier, the average environmental governance efficiency of China's industrial sector from 2010 to 2017 is 0.7810 , of which the average environmental governance efficiency of the high-income groups is 0.8728 , and the average environmental governance efficiency of the same groups is 0.7006 . We see that the overall efficiency of environmental governance in China's industrial sector is relatively high, but there is still a gap between the efficiency of environmental governance in the upper-middle-income groups and high-income groups, which have not reached the national average. In the high-income group, the efficiencies of environmental governance in Beijing, Tianjin, and Shanghai from 2010 to 2017 are 1, realizing effective environmental governance. Provinces and cities showing a downward trend in environmental governance efficiency include Inner Mongolia, Zhejiang, Shandong, and Shaanxi, while provinces and cities showing an upward trend in environmental governance efficiency include Liaoning, Jilin, Jiangsu, Fujian, Hubei, Guangdong, and Chongqing. In the middle- and high-income groups, the environmental governance efficiency of Hainan Province is 1 from 2010 to 2017, thus achieving effective governance of environmental pollution. The provinces and cities showing a downward trend of environmental governance efficiency include Hebei, Shanxi, Heilongjiang, Anhui, Henan, Gansu, and Xinjiang, while the provinces and cities showing an upward trend of environmental governance efficiency include Jiangxi, Hunan, Guangxi, Sichuan, Guizhou, Yunnan, Qinghai, and Ningxia. 
Table 3. China's environmental governance efficiency under the meta frontier and group frontier from 2010 to 2017.

\begin{tabular}{|c|c|c|c|c|c|c|c|c|c|c|c|c|c|c|c|c|c|c|c|}
\hline \multirow{2}{*}{ Cluster } & \multirow{2}{*}{ DMU } & \multicolumn{9}{|c|}{ MTE } & \multicolumn{9}{|c|}{ GTE } \\
\hline & & 2010 & 2011 & 2012 & 2013 & 2014 & 2015 & 2016 & 2017 & Average & 2010 & 2011 & 2012 & 2013 & 2014 & 2015 & 2016 & 2017 & Mean \\
\hline \multirow{14}{*}{$\begin{array}{l}\text { High- } \\
\text { income }\end{array}$} & Beijing & 1.0000 & 1.0000 & 1.0000 & 1.0000 & 1.0000 & 1.0000 & 1.0000 & 1.0000 & 1.0000 & 1.0000 & 1.0000 & 1.0000 & 1.0000 & 1.0000 & 1.0000 & 1.0000 & 1.0000 & 1.0000 \\
\hline & Tianjin & 1.0000 & 1.0000 & 1.0000 & 1.0000 & 1.0000 & 1.0000 & 1.0000 & 1.0000 & 1.0000 & 1.0000 & 1.0000 & 1.0000 & 1.0000 & 1.0000 & 1.0000 & 1.0000 & 1.0000 & 1.0000 \\
\hline & $\begin{array}{l}\text { Inner } \\
\text { Mongolia }\end{array}$ & 1.0000 & 1.0000 & 0.9989 & 0.9796 & 0.9761 & 1.0000 & 0.9275 & 0.8986 & 0.9726 & 1.0000 & 1.0000 & 0.9989 & 0.9796 & 0.9761 & 1.0000 & 0.9279 & 0.9030 & 0.9732 \\
\hline & Liaoning & 0.7947 & 0.8100 & 0.8132 & 0.8236 & 0.7609 & 0.8079 & 0.9726 & 0.9994 & 0.8478 & 0.7947 & 0.8100 & 0.8132 & 0.8236 & 0.7609 & 0.8132 & 0.9779 & 0.9994 & 0.8491 \\
\hline & Jilin & 0.7275 & 0.7673 & 0.7976 & 0.7834 & 0.7718 & 0.7797 & 0.8831 & 0.7745 & 0.7856 & 0.7275 & 0.7673 & 0.7976 & 0.7834 & 0.7718 & 0.7909 & 0.8868 & 0.7957 & 0.7901 \\
\hline & Shanghai & 1.0000 & 1.0000 & 1.0000 & 1.0000 & 1.0000 & 1.0000 & 1.0000 & 1.0000 & 1.0000 & 1.0000 & 1.0000 & 1.0000 & 1.0000 & 1.0000 & 1.0000 & 1.0000 & 1.0000 & 1.0000 \\
\hline & Jiangsu & 0.8339 & 0.8021 & 0.7876 & 0.7673 & 0.7943 & 0.7916 & 0.8333 & 0.9982 & 0.8260 & 0.8510 & 0.8054 & 0.7888 & 0.7674 & 0.7945 & 0.7915 & 0.8335 & 1.0000 & 0.8290 \\
\hline & Zhejiang & 0.8440 & 0.8100 & 0.8074 & 0.7256 & 0.7243 & 0.6924 & 0.7415 & 0.7851 & 0.7663 & 0.8526 & 0.8166 & 0.8101 & 0.7268 & 0.7249 & 0.6928 & 0.7417 & 0.7856 & 0.7689 \\
\hline & Fujian & 0.8135 & 0.7774 & 0.8589 & 0.7888 & 0.7670 & 0.7700 & 0.8086 & 1.0000 & 0.8230 & 0.8671 & 0.8284 & 0.8803 & 0.8285 & 0.8014 & 0.8036 & 0.8483 & 1.0000 & 0.8572 \\
\hline & Shandong & 0.8026 & 0.7856 & 0.7710 & 0.7590 & 0.7596 & 0.7215 & 0.7895 & 0.7386 & 0.7659 & 0.8026 & 0.7856 & 0.7710 & 0.7590 & 0.7596 & 0.7215 & 0.7895 & 0.7386 & 0.7659 \\
\hline & Hubei & 0.6173 & 0.6159 & 0.6259 & 0.6368 & 0.6611 & 0.8212 & 0.7643 & 0.9559 & 0.7123 & 0.6329 & 0.6166 & 0.6264 & 0.6383 & 0.6619 & 0.8217 & 0.7653 & 0.9759 & 0.7174 \\
\hline & Guangdong & 0.9929 & 1.0000 & 0.9638 & 1.0000 & 1.0000 & 1.0000 & 1.0000 & 1.0000 & 0.9946 & 0.9929 & 1.0000 & 0.9649 & 1.0000 & 1.0000 & 1.0000 & 1.0000 & 1.0000 & 0.9947 \\
\hline & Chongqing & 0.9026 & 1.0000 & 1.0000 & 1.0000 & 1.0000 & 1.0000 & 1.0000 & 1.0000 & 0.9878 & 0.9312 & 1.0000 & 1.0000 & 1.0000 & 1.0000 & 1.0000 & 1.0000 & 1.0000 & 0.9914 \\
\hline & Shaanxi & 0.7745 & 0.7741 & 0.8277 & 0.8103 & 0.7885 & 0.6886 & 0.7007 & 0.6638 & 0.7535 & 0.7818 & 0.7758 & 0.8277 & 0.8103 & 0.7885 & 0.6886 & 0.7007 & 0.6669 & 0.7550 \\
\hline \multirow{16}{*}{$\begin{array}{l}\text { Upper- } \\
\text { middle } \\
\text { income }\end{array}$} & Hebei & 0.8151 & 0.7069 & 0.6655 & 0.6416 & 0.6361 & 0.6258 & 0.6876 & 0.6907 & 0.6837 & 1.0000 & 1.0000 & 1.0000 & 1.0000 & 1.0000 & 1.0000 & 1.0000 & 1.0000 & 1.0000 \\
\hline & Shanxi & 0.6952 & 0.7376 & 0.6748 & 0.6269 & 0.5753 & 0.5761 & 0.5420 & 0.6027 & 0.6288 & 1.0000 & 1.0000 & 1.0000 & 1.0000 & 1.0000 & 1.0000 & 1.0000 & 1.0000 & 1.0000 \\
\hline & Heilongiiang & 0.8389 & 0.7383 & 0.7712 & 0.6850 & 0.6947 & 0.6841 & 0.6788 & 0.7717 & 0.7328 & 1.0000 & 1.0000 & 1.0000 & 1.0000 & 1.0000 & 1.0000 & 1.0000 & 1.0000 & 1.0000 \\
\hline & Anhui & 0.7110 & 0.6776 & 0.6627 & 0.6041 & 0.6017 & 0.5774 & 0.6884 & 0.6208 & 0.6430 & 1.0000 & 1.0000 & 1.0000 & 1.0000 & 1.0000 & 1.0000 & 1.0000 & 1.0000 & 1.0000 \\
\hline & Jiangxi & 0.7981 & 0.7790 & 0.7695 & 0.6951 & 0.6681 & 0.6333 & 0.7016 & 0.9323 & 0.7471 & 1.0000 & 1.0000 & 1.0000 & 1.0000 & 1.0000 & 1.0000 & 1.0000 & 1.0000 & 1.0000 \\
\hline & Henan & 0.6469 & 0.6466 & 0.6070 & 0.5972 & 0.6104 & 0.6168 & 0.6735 & 0.5641 & 0.6203 & 1.0000 & 1.0000 & 1.0000 & 1.0000 & 1.0000 & 1.0000 & 1.0000 & 1.0000 & 1.0000 \\
\hline & Hunan & 0.6357 & 1.0000 & 0.7715 & 0.8464 & 1.0000 & 1.0000 & 1.0000 & 1.0000 & 0.9067 & 1.0000 & 1.0000 & 1.0000 & 1.0000 & 1.0000 & 1.0000 & 1.0000 & 1.0000 & 1.0000 \\
\hline & Guangxi & 0.6745 & 0.6576 & 0.6389 & $\begin{array}{l}0.06209 \\
0.6209\end{array}$ & 0.6026 & 0.5970 & 0.6376 & 0.8682 & 0.6621 & 0.8237 & 0.9632 & 0.9684 & 0.9249 & 0.9128 & 0.9276 & 0.9249 & 1.0000 & 0.9307 \\
\hline & Hainan & 1.0000 & 1.0000 & 1.0000 & 1.0000 & 1.0000 & 1.0000 & 1.0000 & 1.0000 & 1.0000 & 1.0000 & 1.0000 & $\begin{array}{l}1.0000 \\
1.0000\end{array}$ & 1.0000 & 1.0000 & 1.0000 & 1.0000 & 1.0000 & 1.0000 \\
\hline & Sichuan & 0.7983 & 0.6673 & 0.7472 & 0.7073 & 0.7110 & 1.0000 & 0.8778 & 1.0000 & 0.8136 & 1.0000 & 1.0000 & 1.0000 & 1.0000 & 1.0000 & 1.0000 & 1.0000 & 1.0000 & 1.0000 \\
\hline & Guizhou & 0.6838 & 0.7942 & 0.6629 & 0.6056 & 0.5831 & 0.6783 & 0.8724 & 1.0000 & 0.7350 & 0.9545 & 1.0000 & 1.0000 & 1.0000 & 1.0000 & 1.0000 & 1.0000 & 1.0000 & 0.9943 \\
\hline & Yunnan & 0.7147 & 0.5553 & 0.5426 & 0.5492 & 0.5686 & 0.5492 & 0.5630 & 1.0000 & 0.6303 & 0.9848 & 0.8447 & 0.9043 & 0.9130 & 0.9178 & 0.8887 & 0.8451 & 0.8895 & 0.8985 \\
\hline & Gansu & 0.6705 & 0.6166 & 0.6479 & 0.6432 & 0.6583 & 0.8516 & 0.6167 & 0.6082 & 0.6641 & 1.0000 & 1.0000 & 1.0000 & 1.0000 & 1.0000 & 1.0000 & 1.0000 & 1.0000 & 1.0000 \\
\hline & Qinghai & 0.6764 & 0.5978 & 0.6473 & 0.6490 & 0.6522 & 0.6460 & 0.5708 & 0.7024 & 0.6428 & 0.8608 & 1.0000 & 1.0000 & 1.0000 & 1.0000 & 1.0000 & 1.0000 & 1.0000 & 0.9826 \\
\hline & Ningxia & 0.4556 & 0.4581 & 0.4673 & 0.4735 & 0.4982 & 0.5776 & 0.5569 & 0.5885 & 0.5095 & 1.0000 & 1.0000 & 1.0000 & 1.0000 & 1.0000 & 1.0000 & 1.0000 & 1.0000 & 1.0000 \\
\hline & Xinjiang & 0.6195 & 0.6594 & 0.6326 & 0.6183 & 0.6422 & 0.6256 & 0.6458 & 0.5608 & 0.6255 & 1.0000 & 1.0000 & 1.0000 & 1.0000 & 1.0000 & 1.0000 & 1.0000 & 0.9485 & 0.9936 \\
\hline
\end{tabular}

(Data source: Authors' collection). 
Under the group frontier, the environmental governance efficiencies of the highincome group and the upper-middle-income group are 0.8766 and 0.9863 , respectively. Compared to the common frontier, efficiency performance has improved, especially the middle-high-income group as it is close to the effective state. This is because the DEA efficiency measurement method evaluates relative efficiency, and the improvement of GTE is the result of the convergence of the frontier boundaries within the group caused by the regrouping of decision-making units on the meta frontier. It is thus necessary to use the meta-frontier method to measure the efficiency of regional environmental governance.

In the high-income group, the efficiencies of environmental governance in Beijing, Tianjin, and Shanghai from 2010 to 2017 are 1, thus realizing effective governance of environmental pollution. Provinces and cities showing a downward trend in environmental governance efficiency include Inner Mongolia, Jiangsu, Zhejiang, Shandong, and Shaanxi, while those showing an upward trend in environmental governance efficiency include Liaoning, Jilin, Fujian, Hubei, Guangdong, and Chongqing. Among the upper-middleincome groups, 11 provinces including Hebei, Shanxi, Heilongjiang, Anhui, Jiangxi, Henan, Hunan, Hainan, Sichuan, Gansu, and Ningxia have achieved group efficiency and effectiveness. Guangxi shows an upward trend in environmental governance efficiency, while Yunnan and Xinjiang show a downward trend in environmental governance efficiency.

\subsection{Analysis of the Technology Gap Ratio}

Based on the calculations of MTE and GTE in various provinces and cities, this paper uses the technology gap ratio (TGR) to analyze the gap in environmental governance efficiency in various regions (see Table 4). According to Tables 2 and 3, the overall and regional findings of China's environmental governance efficiency show that GTE is significantly higher than MTE. The average technology gap efficiency values of the high-income groups and upper-middle-income groups are 0.9951 and 0.7117 , respectively, indicating that there is a gap between each region's actual technology level and the potential best technology level, with $0.49 \%$ and $28.83 \%$ room for improvement, respectively. The actual technology level of the high-income group is closest to the potential best technology level, but there is still a gap between the high-income group and the potential best technology level.

Between 2010 and 2017, among the high-income groups the five provinces of Beijing, Tianjin, Shanghai, Shandong, and Guangdong have a technology gap ratio of 1, indicating that their actual technology level is in the leading position in China and has reached the potential best technology level. The other eight provinces in the high-income group, Inner Mongolia, Jilin, Jiangsu, Zhejiang, Fujian, Hubei, Chongqing, and Shaanxi, all fluctuate within the range of $[0.9,1]$, indicating that they have higher levels of actual technology and are close to the potential best technology level in the country.

Table 4. The technical gap of China's environmental governance efficiency from 2010 to 2017.

\begin{tabular}{ccccccccccc}
\hline Cluster & DMU & $\mathbf{2 0 1 0}$ & $\mathbf{2 0 1 1}$ & $\mathbf{2 0 1 2}$ & $\mathbf{2 0 1 3}$ & $\mathbf{2 0 1 4}$ & $\mathbf{2 0 1 5}$ & $\mathbf{2 0 1 6}$ & $\mathbf{2 0 1 7}$ & Mean \\
\hline & Beijing & 1.0000 & 1.0000 & 1.0000 & 1.0000 & 1.0000 & 1.0000 & 1.0000 & 1.0000 & 1.0000 \\
& Tianjin & 1.0000 & 1.0000 & 1.0000 & 1.0000 & 1.0000 & 1.0000 & 1.0000 & 1.0000 & 1.0000 \\
& Inner Mongolia & 1.0000 & 1.0000 & 1.0000 & 1.0000 & 1.0000 & 1.0000 & 0.9996 & 0.9951 & 0.9993 \\
& Liaoning & 1.0000 & 1.0000 & 1.0000 & 1.0000 & 1.0000 & 0.9936 & 0.9946 & 1.0000 & 0.9985 \\
& Jilin & 1.0000 & 1.0000 & 1.0000 & 1.0000 & 1.0000 & 0.9858 & 0.9959 & 0.9734 & 0.9944 \\
High- & Shanghai & 1.0000 & 1.0000 & 1.0000 & 1.0000 & 1.0000 & 1.0000 & 1.0000 & 1.0000 & 1.0000 \\
income & Jiangsu & 0.9800 & 0.9959 & 0.9985 & 0.9998 & 0.9998 & 1.0000 & 0.9998 & 0.9982 & 0.9965 \\
& Zhejiang & 0.9899 & 0.9919 & 0.9966 & 0.9983 & 0.9991 & 0.9994 & 0.9998 & 0.9994 & 0.9968 \\
& Fujian & 0.9382 & 0.9385 & 0.9757 & 0.9521 & 0.9571 & 0.9583 & 0.9531 & 1.0000 & 0.9591 \\
& Shandong & 1.0000 & 1.0000 & 1.0000 & 1.0000 & 1.0000 & 1.0000 & 1.0000 & 1.0000 & 1.0000 \\
& Hubei & 0.9754 & 0.9989 & 0.9991 & 0.9976 & 0.9988 & 0.9994 & 0.9987 & 0.9794 & 0.9934 \\
& Guangdong & 1.0000 & 1.0000 & 0.9989 & 1.0000 & 1.0000 & 1.0000 & 1.0000 & 1.0000 & 0.9999 \\
& Chongqing & 0.9692 & 1.0000 & 1.0000 & 1.0000 & 1.0000 & 1.0000 & 1.0000 & 1.0000 & 0.9962 \\
& Shaanxi & 0.9906 & 0.9978 & 1.0000 & 1.0000 & 1.0000 & 1.0000 & 1.0000 & 0.9954 & 0.9980 \\
\hline
\end{tabular}


Table 4. Cont

\begin{tabular}{lcccccccccc}
\hline Cluster & DMU & $\mathbf{2 0 1 0}$ & $\mathbf{2 0 1 1}$ & $\mathbf{2 0 1 2}$ & $\mathbf{2 0 1 3}$ & $\mathbf{2 0 1 4}$ & $\mathbf{2 0 1 5}$ & $\mathbf{2 0 1 6}$ & $\mathbf{2 0 1 7}$ & Mean \\
\hline \multirow{6}{*}{} & Hebei & 0.8151 & 0.7069 & 0.6655 & 0.6416 & 0.6361 & 0.6258 & 0.6876 & 0.6907 & 0.6837 \\
& Shanxi & 0.6952 & 0.7376 & 0.6748 & 0.6269 & 0.5753 & 0.5761 & 0.5420 & 0.6027 & 0.6288 \\
& Heilongjiang & 0.8389 & 0.7383 & 0.7712 & 0.6850 & 0.6947 & 0.6841 & 0.6788 & 0.7717 & 0.7328 \\
& Anhui & 0.7110 & 0.6776 & 0.6627 & 0.6041 & 0.6017 & 0.5774 & 0.6884 & 0.6208 & 0.6430 \\
& Jiangxi & 0.7981 & 0.7790 & 0.7695 & 0.6951 & 0.6681 & 0.6333 & 0.7016 & 0.9323 & 0.7471 \\
& Henan & 0.6469 & 0.6466 & 0.6070 & 0.5972 & 0.6104 & 0.6168 & 0.6735 & 0.5641 & 0.6203 \\
Upper- & Hunan & 0.6357 & 1.0000 & 0.7715 & 0.8464 & 1.0000 & 1.0000 & 1.0000 & 1.0000 & 0.9067 \\
middle & Guangxi & 0.8188 & 0.6827 & 0.6597 & 0.6713 & 0.6602 & 0.6435 & 0.6894 & 0.8682 & 0.7117 \\
income & Hainan & 1.0000 & 1.0000 & 1.0000 & 1.0000 & 1.0000 & 1.0000 & 1.0000 & 1.0000 & 1.0000 \\
& Sichuan & 0.7983 & 0.6673 & 0.7472 & 0.7073 & 0.7110 & 1.0000 & 0.8778 & 1.0000 & 0.8136 \\
& Guizhou & 0.7164 & 0.7942 & 0.6629 & 0.6056 & 0.5831 & 0.6783 & 0.8724 & 1.0000 & 0.7391 \\
& Yunnan & 0.7257 & 0.6574 & 0.6001 & 0.6015 & 0.6196 & 0.6179 & 0.6662 & 1.1242 & 0.7016 \\
& Gansu & 0.6705 & 0.6166 & 0.6479 & 0.6432 & 0.6583 & 0.8516 & 0.6167 & 0.6082 & 0.6641 \\
& Qinghai & 0.7858 & 0.5978 & 0.6473 & 0.6490 & 0.6522 & 0.6460 & 0.5708 & 0.7024 & 0.6564 \\
& Ningxia & 0.4556 & 0.4581 & 0.4673 & 0.4735 & 0.4982 & 0.5776 & 0.5569 & 0.5885 & 0.5095 \\
& Xinjiang & 0.6195 & 0.6594 & 0.6326 & 0.6183 & 0.6422 & 0.6256 & 0.6458 & 0.5913 & 0.6293 \\
\hline
\end{tabular}

(Data source: Authors' collection).

Among the middle and high-income groups, the technology gap ratio of Hainan is 1 from 2010 to 2017, indicating that it has achieved the potential best technology level in the country. For Hebei, Shanxi, Heilongjiang, Anhui, Henan, Gansu, Qinghai, and Xinjiang, their technology gap ratios have fluctuated and showed a downward trend. Those with a technology gap ratio that fluctuates and shows an upward trend include seven provinces, Jiangxi, Hunan, Guangxi, Sichuan, Guizhou, Yunnan, and Ningxia.

\subsection{Inefficiency Analysis of Environmental Pollution Control}

In order to further explore the reasons for the inefficiency of environmental governance in various provinces and cities and to provide decision-making reference for improving this inefficiency, we decompose the inefficiency value (IE) of each province and municipality with invalid environmental governance into technical level gap inefficiency (TIE) and management inefficiency (MIE) (see Table 5). According to Table 4, the main reason for the inefficiency of environmental governance in each province in the high-income group is management inefficiency, as technical inefficiency accounts for a small proportion. The main reason for the ineffective environmental governance of the provinces in the middle- and high-income groups is technical inefficiency. Among them, Hebei, Shanxi, Heilongjiang, Anhui, Jiangxi, Henan, Hunan, Sichuan, Gansu, and Ningxia all have technical inefficiency.

Among the high-income groups in 2010, management inefficiencies were the full cause of environmental governance inefficiency for four provinces including Liaoning, Jilin, Shandong, and Guangdong. For other provinces such as Jiangsu, Zhejiang, Fujian, Hubei, Chongqing, and Shaanxi, inefficiency and management inefficiency combined together for environmental governance inefficiency, but with management inefficiency as the main reason. Among the upper-middle-income groups, the environmental governance inefficiencies in 11 provinces including Hebei, Shanxi, Heilongjiang, Anhui, Jiangxi, Henan, Hunan, Sichuan, Gansu, Ningxia, and Xinjiang were entirely due to technical inefficiency. Among them, Guangxi mainly incurs management inefficiency, and Guizhou, Yunnan, and Qinghai mainly experience technical inefficiency.

In the high-income group in 2011, three provinces' environmental governance inefficiencies, including Liaoning, Jilin, and Shandong, were caused entirely by management inefficiency, while the other five provinces such as Jiangsu, Zhejiang, Fujian, Hubei, and Shaanxi were caused by both technical and management inefficiencies. Ineffective management is the main reason for environmental governance inefficiency. Among the highincome groups, the environmental governance inefficiencies of Hebei, Shanxi, Heilongiiang, Anhui, Jiangxi, Henan, Guizhou, Yunnan, Qinghai, Ningxia, and Xinjiang are all due to 
technical inefficiency, while Guangxi and Yunnan are due to technical inefficiency and management inefficiency, but technical inefficiency is still the main reason.

Table 5. Technical and management inefficiency of China's environmental governance.

\begin{tabular}{|c|c|c|c|c|c|c|}
\hline \multirow{2}{*}{ Group } & \multirow{2}{*}{ DMU } & \multirow{2}{*}{ IE } & \multicolumn{2}{|c|}{ TIE } & \multicolumn{2}{|c|}{ MIE } \\
\hline & & & Mean & Percentage & Mean & Percentage \\
\hline \multirow{11}{*}{ High-income } & Inner Mongolia & 0.0279 & 0.0005 & $1.93 \%$ & 0.0274 & $98.07 \%$ \\
\hline & Liaoning & 0.1544 & 0.0001 & $0.05 \%$ & 0.1543 & $99.95 \%$ \\
\hline & Jilin & 0.2147 & 0.0036 & $1.69 \%$ & 0.2111 & $98.31 \%$ \\
\hline & Jiangsu & 0.1759 & 0.0029 & $1.65 \%$ & 0.1730 & $98.35 \%$ \\
\hline & Zhejiang & 0.2346 & 0.0014 & $0.60 \%$ & 0.2332 & $99.40 \%$ \\
\hline & Fujian & 0.1791 & 0.0348 & $19.45 \%$ & 0.1443 & $80.55 \%$ \\
\hline & Shandong & 0.2344 & 0 & $0.00 \%$ & 0.2344 & $100.00 \%$ \\
\hline & Hubei & 0.2932 & 0.0042 & $1.42 \%$ & 0.2890 & $98.58 \%$ \\
\hline & Guangdong & 0.0055 & 0.0001 & $2.42 \%$ & 0.0053 & $97.59 \%$ \\
\hline & Chongqing & 0.0126 & 0.0038 & $30.14 \%$ & 0.0088 & $69.86 \%$ \\
\hline & Shaanxi & 0.2479 & 0.0015 & $0.62 \%$ & 0.2464 & $99.38 \%$ \\
\hline \multirow{15}{*}{$\begin{array}{l}\text { Upper-middle- } \\
\text { income }\end{array}$} & Hebei & 0.3177 & 0.3177 & $100.00 \%$ & 0 & 0 \\
\hline & Shanxi & 0.3731 & 0.3731 & $100.00 \%$ & 0 & 0 \\
\hline & Heilongjiang & 0.2685 & 0.2685 & $100.00 \%$ & 0 & 0 \\
\hline & Anhui & 0.3580 & 0.3580 & $100.00 \%$ & 0 & 0 \\
\hline & Jiangxi & 0.2563 & 0.2563 & $100.00 \%$ & 0 & 0 \\
\hline & Henan & 0.3802 & 0.3802 & $100.00 \%$ & 0 & 0 \\
\hline & Hunan & 0.1009 & 0.1009 & $100.00 \%$ & 0 & 0 \\
\hline & Guangxi & 0.3277 & 0.2410 & $73.56 \%$ & 0.0866 & $26.44 \%$ \\
\hline & Sichuan & 0.1928 & 0.1928 & $100.00 \%$ & 0 & 0 \\
\hline & Guizhou & 0.2727 & 0.2669 & $97.88 \%$ & 0.0058 & $2.12 \%$ \\
\hline & Yunnan & 0.3790 & 0.2768 & $73.03 \%$ & 0.1022 & $26.97 \%$ \\
\hline & Gansu & 0.3382 & 0.3382 & $100.00 \%$ & 0 & 0 \\
\hline & Qinghai & 0.3580 & 0.3397 & $94.89 \%$ & 0.0183 & $5.11 \%$ \\
\hline & Ningxia & 0.4919 & 0.4919 & $100.00 \%$ & 0 & 0 \\
\hline & Xinjiang & 0.3748 & 0.3683 & $98.25 \%$ & 0.0066 & $1.75 \%$ \\
\hline
\end{tabular}

(Data source: Authors' collection).

Among the high-income groups in 2012, the environmental governance inefficiencies of five provinces including Inner Mongolia, Liaoning, Jilin, Shandong, and Shaanxi were caused by inefficient management, while the environmental governance inefficiencies of Jiangsu, Zhejiang, Fujian, Hubei and Guangdong were due to both technology and management, but with management inefficiency as the main reason. Among the highincome groups, the environmental governance inefficiency 13 provinces including Hebei, Shanxi, Heilongjiang, Anhui, Jiangxi, Henan, Hunan, Sichuan, Guizhou, Gansu, Qinghai, Ningxia, and Xinjiang are all due to technical inefficiencies. Guangxi and Yunnan are due to technical inefficiencies. Inefficiency and management inefficiency are caused together, but technical inefficiency is the main cause of inefficiency in environmental governance.

Among the high-income groups in 2013, the environmental governance inefficiencies of Inner Mongolia, Liaoning, Jilin, Shandong, and Shaanxi were caused by ineffective management. The environmental governance inefficiencies of Jiangsu, Zhejiang, Fujian, and Hubei were due to ineffective management. Technical inefficiency is caused by a combination of technologies, but management inefficiency is the main reason. Among the high-income groups, the environmental governance inefficiencies in 13 provinces, including Hebei, Shanxi, Heilongjiang, Anhui, Jiangxi, Henan, Hunan, Sichuan, Guizhou, Gansu, Qinghai, Ningxia, and Xinjiang, were entirely due to technical inefficiency, while for Guangxi and Yunnan they were caused by technical inefficiency and management ineffectiveness, but with technical inefficiency as the main reason.

Among the high-income groups in 2014, the environmental governance inefficiencies of Inner Mongolia, Liaoning, Jilin, and Shandong were caused by ineffective manage- 
ment, while the environmental governance inefficiencies of Jiangsu, Zhejiang, Fujian, and Hubei were due to both ineffective management and technology, but with ineffective management as the main reason. Among the upper-middle-income groups, the environmental governance inefficiencies of 12 provinces including Hebei, Shanxi, Heilongjiang, Anhui, Jiangxi, Henan, Sichuan, Guizhou, Gansu, Qinghai, Ningxia, and Xinjiang were all caused by technical inefficiency, while for Guangxi and Yunnan they were caused by ineffective management and technical ineffectiveness, but with technical inefficiency as the main reason.

In the high-income group in 2015, the environmental governance inefficiencies in Shandong and Shaanxi provinces were entirely caused by ineffective management, and for Liaoning, Jilin, Jiangsu, Zhejiang, Fujian, and Hubei they were caused by ineffective technology and ineffective management, but with ineffective management as the main reason. Among the upper-middle-income groups, the environmental governance inefficiencies of Guangxi and Yunnan were caused by ineffective management and technical ineffectiveness, but with technical inefficiency as the main reason. For Hebei, Shanxi, Heilongjiang, Anhui, Jiangxi, Henan, Sichuan, Guizhou, Gansu, Qinghai, Ningxia, and Xinjiang, the environmental governance inefficiencies were completely caused by technical ineffectiveness.

Among the high-income groups in 2016, the environmental governance inefficiencies of Shandong and Shaanxi provinces were entirely caused by ineffective management, while for Inner Mongolia, Liaoning, Jilin, Jiangsu, Zhejiang, Fujian, and Hubei they were caused by ineffective technology and ineffective management, but with ineffective management as the main reason. Among the upper-middle-income groups, the environmental governance inefficiencies of Guangxi and Yunnan were caused by ineffective management and technical ineffectiveness, but with technical inefficiency as the main reason. For Hebei, Shanxi, Heilongjiang, Anhui, Jiangxi, Henan, Sichuan, Guizhou, Gansu, Qinghai, Ningxia, and Xinjiang, their environmental governance inefficiencies were completely caused by technical inefficiency.

In the high-income group in 2017, the environmental governance inefficiencies of Liaoning and Shandong provinces were caused entirely by ineffective management, entirely caused by technical ineffectiveness for Jiangsu, and caused by technical inefficiency and ineffective management, but with ineffective management as the main reason for Inner Mongolia, Jilin, Zhejiang, Hubei, and Shaanxi. Among the low- and middle-income groups, the environmental governance inefficiency of Xinjiang was caused by ineffective management and technical inefficiency, but with the latter as the main reason. For Hebei, Shanxi, Heilongjiang, Anhui, Jiangxi, Henan, Guangxi, Yunnan, Gansu, Qinghai, and Ningxia, their environmental governance inefficiencies were entirely due to technical inefficiency.

From the perspective of input and output factors, whether for high-income groups or low- and middle-income groups, the environmental governance inefficiency of each province from 2010 to 2017 was due to inefficiency of input factors (see Table 6).

Table 6. Input-output inefficiency value of China's environmental governance.

\begin{tabular}{cccc}
\hline Cluster & DMU & Input_Inefficiency & Output_Inefficiency \\
\hline & Inner Mongolia & 0.0169 & 0.0113 \\
Liaoning & 0.0987 & 0.0658 \\
& Jilin & 0.1409 & 0.0940 \\
Jiangsu & 0.1135 & 0.0757 \\
& Zhejiang & 0.1553 & 0.1035 \\
& Fujian & 0.1158 & 0.0772 \\
& Shandong & 0.1552 & 0.1034 \\
& Hubei & 0.1993 & 0.1329 \\
& Guangdong & 0.0033 & 0.0022 \\
& Chongqing & 0.0076 & 0.0051 \\
& Shaanxi & 0.1651 & 0.1101 \\
\hline
\end{tabular}


Table 6. Cont.

\begin{tabular}{cccc}
\hline Cluster & DMU & Input_Inefficiency & Output_Inefficiency \\
\hline & Hebei & 0.2184 & 0.1456 \\
Shanxi & 0.2631 & 0.1754 \\
& Heilongjiang & 0.1805 & 0.1203 \\
& Anhui & 0.2507 & 0.1671 \\
Upper-middle- & Jiangxi & 0.1713 & 0.1142 \\
income & Henan & 0.2690 & 0.1794 \\
& Guanan & 0.0631 & 0.0421 \\
& Sichuan & 0.2263 & 0.1508 \\
& Guizhou & 0.1253 & 0.0836 \\
& Yunnan & 0.1836 & 0.1224 \\
& Gansu & 0.2680 & 0.1787 \\
& Qinghai & 0.2347 & 0.1565 \\
& Ningxia & 0.2507 & 0.1671 \\
& Xinjiang & 0.3674 & 0.2449 \\
& & 0.2646 & 0.1764 \\
\hline
\end{tabular}

(Data source: Authors' collection).

\section{Conclusions and Policy Implications}

This study uses the meta Dynamic DDF model to measure the environmental efficiency and environmental governance efficiency of China's industrial sector from 2010 to 2017 in terms of overall, sub-regional, and sub-provincial perspectives. We evaluate the technical gaps in regional environmental pollution control and explore environmental governance inefficiency. Our findings help provide a basis for formulating relevant policies. The research conclusions of this paper are as follows.

(1) Among the input factors from 2010 to 2017, the average values of energy efficiency, water use efficiency, and investment efficiency of industrial pollution control show an upward trend, while average energy efficiency shows a downward trend. Among the output factors, China's GDP efficiency and wastewater treatment efficiency show an upward trend, but waste gas treatment efficiency and solid waste treatment efficiency show a downward trend.

(2) Under the common frontier, the average environmental governance efficiency of China's industrial sector was 0.7810 from 2010 to 2017. The level of environmental governance efficiency in China's industrial sector is generally relatively high, but the environmental governance efficiencies of high-income groups and upper-middleincome groups still have a gap that does not reach the national average.

(3) Under the group frontier, the environmental governance efficiencies of the highincome group and the upper-middle-income group have improved compared with the common frontier, especially as the middle-high-income group is close to the effective state. This proves that it is very necessary to use the Meta-frontier method to measure the efficiency of regional environmental governance.

(4) The average technology gap efficiency values of the high-income group and the upper-middle-income group in China's environmental governance efficiency are 0.9951 and 0.7117 , respectively. This denotes that the high-income group's actual technology level is closest to the potential best technology level, whereas the uppermiddle-income group is far from the potential best level. There is still a gap in its best technology level.

(5) The main reason for the environmental governance inefficiency of each province in the high-income group is that management is invalid, and the proportion of technical inefficiency is relatively small. The main reason for the environmental governance inefficiency of the provinces in the middle- and high-income groups is technical inefficiency. From the perspective of input and output factors, whether for high-income groups or upper-middle-income groups, the environmental governance inefficiency in each province is caused by inefficiency of the input factors. 
Based on the above research, the policy recommendations are as follows:

(1) Improve the investment plan for environmental pollution control, and continue to increase the human, financial, material, and technical investment in environmental pollution control. Increasing financial expenditures for environmental pollution control, while attracting social capital, broadening the sources of environmental protection funds, actively guiding social capital into the field of environmental protection, promoting the diversification of environmental protection investment entities, and providing a strong economic guarantee for improving the level of environmental pollution control; Improve the weak environment of environmental pollution control, especially the capital investment in waste gas and solid waste control, improve the utilization efficiency of investment funds, and realize the effective allocation of environmental pollution control.

(2) In view of the gap in environmental pollution control efficiency between high-income groups and high-income groups, and between different provinces and cities, the investment direction and investment direction of environmental pollution control should be adjusted according to local conditions according to the environmental pollution status and resource conditions of each region. In addition, each region needs to strengthen the complementarity of resource advantages, establish and improve a cross-regional linkage mechanism for environmental governance, promote the establishment and implementation of the ecological compensation horizontal transfer payment system, and realize the mutual transfer of financial funds between local governments, thereby promoting the various regions in China's coordination of the economy and environment for a win-win situation.

(3) Intensify technological innovation in the field of environmental protection, actively cultivate and introduce high-level talents, and effectively improve the efficiency of China's environmental pollution control. Continue to increase scientific research investment in environmental governance in various provinces and cities in China, adhere to the combination of industry, university and research, develop new technologies for environmental governance, increase technological innovation projects, support the development of high-tech industries, and efficiently utilize the input and output of scientific and technological elements in environmental governance to promote the steady improvement of environmental governance efficiency in various provinces and cities through technological progress.

(4) Strengthen government environmental law enforcement, establish and improve public environmental protection supervision mechanisms, and improve environmental pollution control and management. Implement the most stringent environmental protection system and conduct regular assessments, incorporate an environmental protection into the comprehensive assessment and evaluation system for provincial and municipal leaders, and encourage governments at all levels to strengthen environmental protection enforcement. At the same time, improve the social supervision mechanism, effectively use the power of social supervision, such as public opinion supervision by the news media, and actively organize the broad masses of the people and other social forces to participate in and supervise environmental governance in an orderly manner.

(5) Optimize the industrial structure, promote industrial upgrading, actively transform China's economic development mode, and achieve green growth of the regional economy. Promote the technological transformation and product upgrade of traditional entrepreneurship, and do a good job in energy conservation and emission reduction in industrial industries. Develop high-tech industries, transform low-end industries, promote the sound and rapid development of energy-saving and environmentallyfriendly industries, implement clean enterprise production, prevent pollution from the source, and protect the ecological environment. 
Author Contributions: Conceptualization, X.-N.L. and P.-Y.W.; Methodology, X.-N.L.; Software, Y.-H.C.; Validation, X.-N.L., Y.-H.C. and P.-Y.W.; Formal Analysis, X.-N.L.; Investigation, Y.-H.C.; Resources, Y.F. and P.-Y.W.; Data Curation, Y.F.; Writing-Original Draft Preparation, Y.F.; WritingReview \& Editing, Y.F.; Visualization, Y.F. and P.-Y.W.; Supervision, Y.-H.C.; Project Administration, P.-Y.W. All authors have read and agreed to the published version of the manuscript.

Funding: This research was funded by the project of "Young Academic Innovation Team of Northwest University of Political Science and Law", Poverty Reduction Effect and Long Term Optimization Mechanism of Targeted Poverty Alleviation (2020d036), Economic growth and sustainable utilization of water resources in Shaanxi Province (2020KJXX-038), Efficiency Evaluation and Improvement of Urban Wastewater Treatment in Shaanxi Province (2015D064), Environmental protection and economic growth in the Yellow River Basin (20ZD195-180), Mechanism of Government Resources and Environment Audit to Promote the Construction of Ecological Civilization (2019S029), Definition of Leading Cadres' Responsibility for Resources and Environment Audit based on Ecological Carrying Capacity (2019M663953XB).

Institutional Review Board Statement: Not applicable.

Informed Consent Statement: Not applicable.

Data Availability Statement: Not applicable.

Conflicts of Interest: The authors declare no conflict of interest.

\section{References}

1. Zheng, Y.; Zhao, X.-X. Technical Efficiency of Environment, Pollution Abatement and Environmental Performance-Based on 1998-2012 Provincial Data Analysis. Chin. J. Manag. Sci. 2014, 22, 767-773.

2. Zeng, X.; Niu, M. Environmental efficiency evaluation of Chinese cities under the condition of high quality development. China Environ. Sci. 2019, 39, 2667-2677.

3. Tu, Z.; Shen, R. Does Environment Technology Efficiency Measured by Traditional Method Underestimate Environment Governance Efficiency? From the Evidence of China's Industrial Provincial Panel Data Using Environmental Directional Distance Function Based on the Network DEA Model. Econ. Rev. 2013, 5, 89-99.

4. Song, M.; Peng, J.; Wang, J.; Zhao, J. Environmental efficiency and economic growth of China: A Ray slack-based model analysis. Eur. J. Oper. Res. 2017, 22, 23-28. [CrossRef]

5. Zhang, N.; Choi, Y. Environmental Energy Efficiency of China's Regional Economies: A non-oriented slacks-based measure analysis. Soc. Sci. J. 2013, 50, 225-234. [CrossRef]

6. Chen, L.; Jia, G. Environmental efficiency analysis of China's regional industry: A data envelopment analysis (DEA) based approach. J. Clean. Prod. 2017, 142, 846-853. [CrossRef]

7. Wu, J.; Yin, P.; Sun, J.; Chu, J.; Liang, L. Evaluating the Environmental Efficiency of a Two-stage System with Undesired Outputs by a DEA Approach: An Interest Preference Perspective. Eur. J. Oper. Res. 2016, 254, 1047-1062. [CrossRef]

8. Yao, X.; Guo, C.; Shao, S.; Jiang, Z. Total-factor $\mathrm{CO}_{2}$ emission performance of China's provincial industrial sectors: A meta-frontier non-radial Malmquist index approach. Appl. Energy 2016, 184, 1142-1153. [CrossRef]

9. Castellet, L.; Molinos-Senante, M. Efficiency assessment of wastewater treatment plants: A data envelopment analysis approach integrating technical, economic, and environmental issues. J. Environ. Manag. 2016, 167, 160-166. [CrossRef]

10. D'Inverno, G.; Carosi, L.; Romano, G.; Guerrini, A. Water pollution in wastewater treatment plants: An efficiency analysis with undesirable output. Eur. J. Oper. Res. 2018, 269, 24-34. [CrossRef]

11. Feng, Y.; Chiu, Y.-h.; Liu, F.-p. Measuring the performance of wastewater treatment in China. Appl. Sci. 2019, 9, 153. [CrossRef]

12. Liu, H.; Yang, R.; Zhou, Z.; Huang, D. Regional Green Eco-Efficiency in China: Considering Energy Saving, Pollution Treatment, and External Environmental Heterogeneity. Sustainability 2020, 12, 7059. [CrossRef]

13. Wu, J.; Li, M.; Zhu, Q.; Zhou, Z.; Liang, L. Energy and environmental efficiency measurement of china's industrial sectors: A dea model with non-homogeneous inputs and outputs. Energy Econ. 2019, 78, 468-480. [CrossRef]

14. Zhang, R.; Lu, C.-C.; Lee, J.-H.; Feng, Y.; Chiu, Y.-H. Dynamic Environmental Efficiency Assessment of Industrial Water Pollution. Sustainability 2019, 11, 3053. [CrossRef]

15. Wang, M.; Feng, C. Regional total-factor productivity and environmental governance efficiency of China's industrial sectors: A two-stage network-based super DEA approach. J. Clean. Prod. 2020, 273, 123110. [CrossRef]

16. Song, M.L.; An, Q.X.; Zhang, W.; Wang, Z.Y.; Wu, J. Environmental efficiency evaluation based on data envelopment analysis: A review. Renew. Sustain. Energy Rev. 2012, 16, 4465-4469. [CrossRef]

17. Vlontzos, G.; Niavis, S.; Manos, B. A DEA approach for estimating the agricultural energy and environmental efficiency of EU countries. Renew. Sustain. Energy Rev. 2014, 40, 91-96. [CrossRef]

18. Chang, Y.T.; Park, H.S.; Jeong, J.B.; Lee, J.W. Evaluating economic and environmental efficiency of global airlines: A SBM-DEA approach. Transp. Res. Part D Transp. Environ. 2014, 27, 46-50. [CrossRef] 
19. Lorenzo-Toja, Y.; Vázquez-Rowe, I.; Marín-Navarro, D.; Crujeiras, R.M.; Moreira, M.T.; Feijoo, G. Dynamic environmental efficiency assessment for wastewater treatment plants. Int. J. Life Cycle Assess. 2018, 23, 357-367. [CrossRef]

20. Farrell, M. The Measurement of Productive Efficiency. J. R. Stat. Soc. 1957, 120, 253-281. [CrossRef]

21. Charnes, A.; Cooper, W.W.; Rhodes, E. Measuring the efficiency of decision making units. Eur. J. Oper. Res. 1978, 2, 429-444. [CrossRef]

22. Banker, R.D.; Charnes, A.; Cooper, W. Some Models for Estimating Technical and Scale Inefficiency in Data Envelopment Analysis. Manag. Sci. 1984, 30, 1078-1092. [CrossRef]

23. Tone, K. A slacks-based measure of efficiency in data envelopment analysis. Eur. J. Oper. Res. 2001, 130, 498-509. [CrossRef]

24. Chung, Y.H.; Färe, R.; Grosskopf, S. Productivity and undesirable outputs: A directional distance function approach. J. Environ. Manag. 1997, 51, 229-240. [CrossRef]

25. Färe, R.; Grosskopf, S. Directional distance functions and slacks-based measures of efficiency: Some clarifications. Eur. J. Oper. Res. 2010, 206, 702. [CrossRef]

26. Chen, M.J.; Chiu, Y.H.; Jan, C.L.; Chen, Y.C.; Liu, H.H. Efficiency and risk in commercial banks-Hybrid DEA estimation. Glob. Econ. Rev. 2015, 44, 335-352. [CrossRef]

27. Kloop, G. The Analysis of the Efficiency of Production System with Multiple Inputs and Outputs. Ph.D Thesis, University of Illinois at Chicago, Industrial and Systems Engineering College, Chicago, IL, USA, 1985.

28. Färe, R.; Grosskopf, S. Productivity and intermediate products: A frontier approach. Econ. Lett. 1996, 50, 65-70. [CrossRef]

29. Tone, K.; Tsutisui, M. Dynamic DEA: A slack-based measure approach. Omega 2010, 38, 145-156. [CrossRef]

30. Battese, G.E.; Prasada Rao, D.S. Technology Gap, Efficiency, and a Stochastic Metafrontier Function. Int. J. Bus. Econ. 2002, 1, 87-93.

31. Battese, G.E.; Prasada Rao, D.S.; O’Donnell, C.J. A Metafrontier Production Function for Estimation of Technical Efficiencies and Technology Gaps for Firms Operating Under Different Technologies. J. Product. Anal. 2004, 21, 91-103. [CrossRef]

32. O'Donnell, C.J.; Prasada Rao, D.S.; Battese, G.E. Metafrontier frameworks for the study of firm-level efficiencies and technology ratios. Empir. Econ. 2008, 34, 231-255. [CrossRef]

33. Hu, J.L.; Wang, S.C. Total-factor energy efficiency of regions in China. Energy Policy 2006, 34, 3206-3217. [CrossRef]

34. Li, Y.; Sun, L.; Feng, T.; Zhu, C. How to reduce energy intensity in China: A regional comparison perspective. Energy Policy 2013 61, 513-522. [CrossRef]

35. Wang, K.; Wei, Y.-M.; Zhang, X. Energy and Emissions Efficiency Patterns of Chinese Regions: A Multi-Directional Efficiency Analysis. Appl. Energy 2013, 104, 105-116. [CrossRef]

36. Du, K.; Xie, C.; Ouyang, X. A Comparison of Carbon Dioxide $\left(\mathrm{CO}_{2}\right)$ Emission trends among provinces in China. Renew. Sustain. Energy Rev. 2017, 73, 19-35. [CrossRef]

37. Wang, Q.; Chiu, Y.-H.; Chiu, C.-R. Non-Radial metafrontier approach to identify Carbon Emission Performance and intensity. Renew. Sustain. Energy Rev. 2017, 69, 664-672. [CrossRef] 